\title{
In Situ Structural Characterization of Ageing Kinetics in Aluminum Alloy 2024 across
} Angstrom-to-Micrometer Length Scales

Fan Zhang ${ }^{1, *}$, Lyle E. Levine ${ }^{1}$, Andrew J. Allen ${ }^{1}$, Carelyn E. Campbell ${ }^{1}$, Adam A. Creuziger ${ }^{1}$, Nataliya Kazantseva $^{1,2}$, and Jan Ilavsky ${ }^{3}$

1. Materials Measurement Laboratory, National Institute of Standards and Technology, 100 Bureau Drive, Gaithersburg, MD 20899, USA;

2. Institute of Metal Physics, Urals Branch of the Academy of Sciences, Ekaterinburg 620219, Russia.

3. X-ray Science Division, Argonne National Laboratory, 9700 S. Cass Avenue, Argonne, IL 60439, USA.

\begin{abstract}
:
The precipitate structure and precipitation kinetics in an Al-Cu-Mg alloy (AA2024) aged at 190 ${ }^{\circ} \mathrm{C}, 208{ }^{\circ} \mathrm{C}$, and $226{ }^{\circ} \mathrm{C}$ have been studied using ex situ Transmission Electron Microscopy (TEM) and in situ synchrotron-based, combined ultra-small angle X-ray scattering, small angle X-ray scattering (SAXS), and wide angle X-ray scattering (WAXS) across a length scale from sub-Angstrom to several micrometers. TEM brings information concerning the nature, morphology, and size of the precipitates while SAXS and WAXS provide qualitative and quantitative information concerning the time-dependent size and volume fraction evolution of the precipitates at different stages of the precipitation sequence. Within the experimental time resolution, precipitation at these ageing temperatures involves dissolution of nanometer-sized small clusters and formation of the planar $S$ phase precipitates. Using a three-parameter scattering model constructed on the basis of TEM results, we established the temperaturedependent kinetics for the cluster-dissolution and S-phase formation processes simultaneously. These two processes are shown to have different kinetic rates, with the cluster-dissolution rate approximately double the S-phase formation rate. We identified a dissolution activation energy at $(149.5 \pm 14.6) \mathrm{kJ} \mathrm{mol}^{-1}$, which translates to $(1.55 \pm 0.15) \mathrm{eV} /$ atom, as well as an activation energy for the formation of $\mathrm{S}$ precipitates at $(129.2 \pm 5.4) \mathrm{kJ} \mathrm{mol}^{-1}$, i.e. $(1.33 \pm 0.06) \mathrm{eV} / \mathrm{atom}$. Importantly, the SAXS/WAXS results show the absence of an intermediate Guinier-Preston Bagaryatsky 2 (GPB2)/S" phase in the samples under the experimental ageing conditions. These results are further validated by precipitation simulations that are based on Langer-Schwartz theory and a Kampmann-Wagner numerical method.
\end{abstract}

Key Words: Al-Cu-Mg alloys, Precipitates, Kinetics, in situ, Small Angle X-ray Scattering

*Corresponding author: Fan Zhang, fan.zhang@nist.gov, 1-301-975-5734 


\section{Introduction}

The 2000 series aluminum alloys are important advanced functional materials due to their high yield strength, good fracture toughness and excellent fatigue properties. [1] The mechanism that accounts for these superior material characteristics is precipitation hardening, in which a heat treatment process produces fine precipitates due to changes in solid solute atom solubility in a supersaturated solid solution. [2] The presence of these fine precipitates, in turn, provides barriers to the motion of dislocations, thereby increasing the resistance of the alloy to plastic deformation.

Due to the extremely important role that the 2000 series aluminum alloys play in the aviation industry, much attention has been devoted to understanding their structures and properties. [3-5] Particularly, comprehensive investigations have been made to elucidate the morphological dependence of the precipitates on material composition [6], thermal treatment history [7], and impurity elements [8] to optimize the materials performance for designed applications. To achieve this, ex situ methods such as transmission electron microcopy (TEM) [4, 9], three dimensional atom probe $[10,11]$, and X-ray diffraction [12] have been used to examine the precipitate structure and morphology. Indirect methods such as hardness testing [13], specific resistivity [14], electrical conductivity [15], and differential scanning calorimetry [16] have also been used to provide information associated with the changes in the quantity of the precipitates. From a structure-characterization point of view, an in situ direct investigation of the entire precipitation process over all the relevant length scales, which acts to reveal the morphology and kinetic growth mode of the precipitation phases, remains elusive.

At the same time, despite the large amount of experimental, theoretical, and modeling effort which allows the precipitation processes to be understood on an atomic scale, the complete 
precipitation sequence in $\mathrm{Al}-\mathrm{Cu}-\mathrm{Mg}$ based aluminum alloys (AA20x4 series alloys) is still in debate. $[9,16-18]$ For example, one of the possible precipitation sequences proceeds as follows: supersaturated solid solution $\rightarrow$ co-clusters/Guinier-Preston Bagaryatsky (GPB) zones $\rightarrow$ GPB2 zone/S" $\rightarrow \mathrm{S}^{\prime} \rightarrow \mathrm{S}$. $[2,19]$ In this sequence, the co-clusters are predominantly a Cu-Mg binary phase and are transient. [20] The $\mathrm{S}$ phase, which is the thermal equilibrium phase, has an established crystal composition of $\mathrm{CuMgAl}_{2}$. [20] $\mathrm{S}^{\prime}$ has a crystal structure almost identical to that of the S phase, but is semi-coherent and slightly strained. Additionally, in Al-Cu-Mg alloys, the precipitation hardening is thought to be a two-stage process. In the first stage, the rapid formation of $\mathrm{Mg}-\mathrm{Cu}$ co-clusters is responsible for the initial age hardening. [21, 22] The second stage in the sequence accompanies the formation of the thermodynamic-equilibrium S phase, and does not finish until the transition towards S phase is complete. [2] It is also known that under identical physical and chemical conditions, the second stage requires a significantly longer time to complete. What is controversial is the presence of a transient, nonequilibrium phase of GPB2 zone/ $\mathrm{S}^{\prime \prime}$. To settle this debate, again, it calls for a direct and in situ probe that is capable of characterizing the entire precipitation process.

To meet these challenges, we sought to perform a systematic investigation of the formation kinetics and structure evolution of the precipitates in a commercial aluminum alloy 2024 (AA2024), mostly using synchrotron-based in situ small angle X-ray scattering (SAXS) and diffraction techniques. SAXS, as a scattering technique, examines the structural inhomogeneities within the materials under investigation. It is known to be highly sensitive to very small precipitates in alloys [23-26]. When combined with simultaneous in situ diffraction experiments, it offers an opportunity to unveil the structural transformations of the precipitates in AA2024. 
From a technique point of view, it has been over 60 years since Guinier's pioneering studies of precipitates in alloys using SAXS $[27,28]$. Nevertheless, it is important to recognize that the low X-ray flux from lab-based X-ray sources makes in situ and in operando characterization of precipitate formation processes challenging, if not completely impossible, and a fixed X-ray energy may present problems with X-ray fluorescence that is usually difficult to mitigate. Synchrotron sources, with their energy tunability and high X-ray flux, overcome these restrictions and greatly expand the applicability of SAXS in probing the static morphology and kinetics of precipitates in alloys. Despite this, other hurdles still exist. For example, precipitates in alloys often have multiple length scales, complex shapes, and high volume concentrations. Elucidating these parameters in situ often involves a scattering-vector magnitude, $q$, range (where $q=(4 \mathrm{p} / l) \times \sin (\theta)$, with $2 \theta$ being the scattering angle and $l$ being the X-ray wavelength) that is not commonly accessible using a pinhole SAXS camera setup alone, and the determination of scattering background, necessary for characterization of small precipitates such as Guinier-Preston zones or cluster defects, often requires the scattering intensity to be extended to higher $q$ regimes to determine the level of thermal fluctuations and instrumental background scattering [29]. These requirements demand new measurement capabilities.

To address these needs, we have recently developed an in situ, synchrotron-based measurement technique that is capable of rapidly quantifying atomic structures and microstructures over a size range from less than $0.5 \AA$ up to $\approx 30 \mu \mathrm{m}$. Employing this technique, in conjunction with TEM and thermodynamic modeling, we have investigated the precipitate growth and dissolution kinetics in solution-annealed AA2024 under different artificial ageing conditions. With the unprecedented scale range that this technique covers, we were able to follow, for the first time, the in situ, simultaneous growth of the S precipitates and dissolution of GPB zones/small clusters 
in AA2024 alloys under different isothermal ageing conditions and resolve the evolution of the precipitates both in atomic structure and in microstructure. It is worth noting that many critical aspects of the performance of AA2024 alloys, such as mechanical behavior [30, 31], resistance to corrosion [32], etc. are closely related to the microstructures that emerge at different processing states. Therefore, it is vital to understand the microstructures across all relevant length scales for the ultimate goal of comprehensive material design and optimization.

In the next section, we will briefly introduce the details of the materials, the characterization techniques, experimental procedures, and computational methods. We will then discuss the data reduction and analysis procedure, followed by a presentation of our detailed experimental results and finally offer some concluding remarks.

\section{Materials and Methods}

\subsection{Materials}

Commercially available bare T3-temper aluminum alloy 2024 (AA2024) sheets were acquired and used for the experiments discussed in this paper. The AA2024 sheets were manufactured by AMAG rolling ${ }^{1}$ and meet the standard specification of ASTM B209 [33]. The nominal thickness of the sheet was $0.508 \mathrm{~mm}(0.020$ inch). The as-received alloy was cut into pieces of $\approx 5 \mathrm{~mm} \times 5$ $\mathrm{mm}$.

\subsection{In situ USAXS/SAXS/WAXS Experiments}

This technique is based on the ultra-small angle X-ray scattering (USAXS) instrument at the Advanced Photon Source (APS), Argonne National Laboratory and combines USAXS with pinhole-camera-based small-angle X-ray scattering and wide-angle X-ray scattering (WAXS).

\footnotetext{
${ }^{1}$ Certain commercial equipment, instruments, software or materials are identified in this paper to foster understanding. Such identification does not imply recommendation or endorsement by the Department of Commerce or the National Institute of Standards and Technology, nor does it imply that the materials or equipment identified are necessarily the best available for the purpose.
} 
We conducted our measurements at the USAXS beamline 15-ID at the APS. [34] This instrument makes use of Bonse-Hart type double-crystal optics and extends the scattering vector range of small-angle X-ray scattering (SAXS) down to $10^{-4} \AA^{-1}\left(\approx 2 \times 10^{-5} \AA^{-1}\right.$ when using higher energy X-rays [35]), which is normally inaccessible to pinhole SAXS cameras. Additionally, the scattering intensity from a Bonse-Hart instrument is absolute calibrated, i.e., we measure the quantitative differential scattering cross section, a characteristic property of the sample material, without the need for a separate scattering intensity standard. We used collimated, monochromatic X-rays in the standard 1-D collimated transmission geometry to measure the scattering intensity as a function of $q$. In our experiments, the X-ray wavelength was $0.738 \AA$, which corresponds to an X-ray energy of $16.80 \mathrm{keV}$. The beam size was $0.8 \mathrm{~mm} \times 0.8 \mathrm{~mm}$, and the X-ray flux was $\approx$ $10^{13} \mathrm{photon} / \mathrm{s}$. The measured USAXS $q$ range was from $1 \times 10^{-4} \AA^{-1}$ to $0.2 \AA^{-1}$.

To provide better statistics and a lower scattering background at high $q$, we used a PILATUS 100K detector (Model: 100K-S, Dectris, Baden, Switzerland) [36] in a conventional pinhole small-angle scattering geometry. To match the detector pixel size of $172 \mu \mathrm{m} \times 172 \mu \mathrm{m}$, we set the beam size at $0.15 \mathrm{~mm} \times 0.15 \mathrm{~mm}$. With a sample to detector distance $\approx 534 \mathrm{~mm}$, this pinhole SAXS camera coves a $q$ range from $\approx 0.03 \AA^{-1}$ to $\approx 1.3 \AA^{-1}$. We set the exposure time for each SAXS frame at $20 \mathrm{~s}$ to maximize counting statistics without saturating the detector. The $q$ calibration was conducted using a silver behenate calibration standard. The combination of USAXS and pinhole SAXS measurements enables a better and more accurate measurement of an extended-range SAXS profile, including a better determination of the scattering background, from $1 \times 10^{-4} \AA^{-1}$ to $1.3 \AA^{-1}$. More details about this setup can be found elsewhere. [37] To evaluate the growth of crystalline precipitates formed in AA2024 during the ageing process, we made use of a second PILATUS $100 \mathrm{~K}$ detector to measure wide angle X-ray scattering 
(WAXS) in a $q$ range between $\approx 1.2 \AA^{-1}$ and $\approx 4.3 \AA^{-1}$. The sample-to-detector distance for the WAXS camera was $199 \mathrm{~mm}$. Similar to SAXS, we set the beam size at $0.15 \mathrm{~mm} \times 0.15 \mathrm{~mm}$. For each WAXS frame, the exposure time was $30 \mathrm{~s}$. We calibrated the $q$ values and sample-todetector distances using two sets of NIST standard reference materials: 640d (Si) [38] and 660a (LaB 6 : lanthanum hexaboride) [39]. The combination of overlapping USAXS+SAXS+WAXS measurements thus provides a seamless $q$ range from $1 \times 10^{-4} \AA^{-1}$ to $4.3 \AA^{-1}$, with a corresponding intensity range of about 10 decades.

Prior to in situ measurements, the specimens were solid-solutionized in air at $(535 \pm 1){ }^{\circ} \mathrm{C}$ for at least $3 \mathrm{~h}$, and then quenched in water to room temperature. [20, 40, 41]. The specimens were then immediately transferred to a sample cell, in which the temperature was controlled by a Linkam TH600 thermal stage (Linkam Scientific Instruments Ltd., Tadworth, UK) with a temperature resolution of $0.1{ }^{\circ} \mathrm{C}$. We performed three sets of in situ experiments to follow the formation of the precipitates at isothermal ageing temperatures of $190{ }^{\circ} \mathrm{C}, 208{ }^{\circ} \mathrm{C}$, and $226{ }^{\circ} \mathrm{C}$, respectively. These temperatures were chosen such that they are within the suitable temperature range for precipitation heat treating. [42] The heating rate from room temperature to the target temperatures was set at $50{ }^{\circ} \mathrm{C}$ per minute.

For each ageing series, we conducted the combined measurements in a repeated sequence of USAXS, SAXS, and WAXS. It took $\approx 12 \mathrm{~min}$ for each set of combined measurements. Depending on the ageing temperature, we allowed the total ageing time to vary between $9 \mathrm{~h}$ and $13 \mathrm{~h}$. As an empirical criterion for the determination of the measurement duration to completion at any one temperature, we required no substantial changes to be observed for the last three consecutive USAXS datasets versus ageing time.

\subsection{Ex situ TEM Experiments}


To properly construct a scattering model, a detailed understanding of the typical morphology and composition of the constituent phases of AA2024 after the solid-solutionization and ageing process is required. For this purpose, we prepared TEM samples following a similar samplepreparation protocol to the combined USAXS/SAXS/WAXS study. For the data shown in this paper, TEM samples, after thinning, were solutionized at $535^{\circ} \mathrm{C}$ for $5 \mathrm{~h}$, and then quenched in water to room temperature. Subsequently, the samples were aged at an isothermal annealing temperature of $226^{\circ} \mathrm{C}$ for $9 \mathrm{~h}$. After another water-quench, the samples were examined at room temperature using a JEOL JEM 3010 microscope (Nanolab Technologies, Milpitas, CA).

\subsection{Thermodynamic modeling}

The development and evolution of numerical methods in recent years have made it possible to not only predict material properties but also accelerate materials discovery and deployment. Particularly, computational thermodynamics modeling enables a direct correlation between microstructure, processing, chemistry, crystallography, kinetics and material thermodynamics. To elucidate the observed precipitation kinetics in the current experiment, we have modeled the precipitation kinetics using TC-PRISMA precipitation software code [43-45]. TC-PRISMA applies Langer-Schwartz theory [46] and Kampann-Wagner numerical analysis [47, 48] to simulate the nucleation and growth of precipitates in multicomponent and multiphase alloy systems., where the time-dependent evolution of the particle size and volume fraction over the entire course of precipitation are predicted by solving a set of rate equations. We used Al-alloy databases TCAL4 [49] and MOBAL3 [50] for thermodynamic and diffusion mobility parameters, respectively.

\section{Results and Discussion}

\subsection{Composition and Precipitate Morphologies}


The chemical composition of the AA2024 alloy specimens used in this study is listed in Table 1. These data were obtained using standard test methods for analysis of aluminum and aluminum alloys by spark atomic emission spectrometry, consistent with ASTM E1251 Test Standards.[51] The alloys were supplied in the form of bare T3-temper AA2024 sheet. Both the Fe and Si contents identified in this analysis were close to the maximum values $(0.5 \%$ mass for each) allowed for AA2024.

The AA2024 alloy we studied resides in the $\alpha+\mathrm{S}$ field of the ternary Al-Cu-Mg phase diagram. [52] We performed comprehensive TEM investigations on the heat-treated AA2024 specimens to identify the types of constituent phases present in the sample, reveal the overall grain structure, and discriminate among the various morphologies that emerged.

Figure 1 shows dark-field TEM micrographs of the constituent phases identified in the AA2024 sample under TEM-226 conditions (details of heat treatments for all specimens used in this study are listed in Table 2) and their corresponding selected-area electron diffraction (SAED) patterns. These phases include $\mathrm{CuMgAl}_{2}$ ( $\mathrm{S}$ phase), $\mathrm{Al}_{12}(\mathrm{Fe}, \mathrm{Mn})_{3} \mathrm{Si}, \mathrm{Al}_{7} \mathrm{Cu}_{2} \mathrm{Fe}, \mathrm{Mg}_{2} \mathrm{Si}(\beta$ phase), $\mathrm{AlFeMgSi}$, and $\mathrm{Al}_{2} \mathrm{Cu}$ ( $\theta$ phase). The presence of these phases is consistent with previous findings [53, 54], where most of these constituent phases have already been previously identified using X-ray and electron diffraction methods. However, we note that, to the best of our knowledge, AlFeMgSi has not been described previously, and its presence here may be associated with the relatively high concentration of $\mathrm{Fe}$ and $\mathrm{Si}$ and the specific processing conditions this commercial alloy received during the manufacturing process.

We determined both the phase compositions and lattice parameters of the constituent phases based on the TEM diffraction patterns. These results are shown in Table 3. We note that all these results were obtained with the TEM-226 sample at room temperature. Particularly, although 
there is evidence in the literature [20] that suggests two types of S precipitates could co-exist in $\mathrm{Al}-\mathrm{Cu}-\mathrm{Mg}$ alloys ( $\mathrm{S}$ and $\mathrm{S}^{\prime}$ ), it is also accepted that the crystal structures of the two phases are almost identical, and the main difference is that the $\mathrm{S}^{\prime}$ phase is semi-coherent with the matrix. For this reason, many recent publications make no distinction between the $\mathrm{S}$ phase and the $\mathrm{S}^{\prime}$ phase. In our analysis here and below, we do not attempt to distinguish between $\mathrm{S}$ and $\mathrm{S}^{\prime}$ precipitates. Despite the large number of constituent phases we identified, we note that their estimated number densities vary greatly, with the equilibrium $\mathrm{S}$ phase being the most common. We also found that the crystal structure of the S phase, determined from our TEM measurements, is very close to that proposed by the widely-accepted Perlitz-Westgren model, which shows that $\mathrm{S}$ precipitates have a composition of $\mathrm{CuMgAl}_{2}$ and an orthorhombic structure $(\mathrm{Cmcm}$ space group with lattice parameters of $a=0.400 \mathrm{~nm}, b=0.923 \mathrm{~nm}$, and $c=0.714 \mathrm{~nm}$ ). [55] With the structure and composition of the S phase, we calculated its mass density. Using this information, Table 4 summarizes the calculated X-ray scattering length densities and contrasts for the S phase in an FCC aluminum matrix.

As a side note relevant to the SAXS analysis later on, we identified large insoluble constituent phases (greater than $3 \mu \mathrm{m}$ in size) such as $\mathrm{Al}_{7} \mathrm{Cu}_{2} \mathrm{Fe}$ using TEM. Such insoluble constituent phases are undesirable due to their overall negative impact on the mechanical properties of the alloys. However, their existence is inevitable for commercial alloys because the cost to reduce the total impurity level below that for maximum solubility is often prohibitively high. For Al-Cu$\mathrm{Mg}$ alloys such as AA2024, the insoluble constituent phases mostly arise from Fe or $\mathrm{Si}$ impurities, due to the low solubility of Fe and $\mathrm{Si}$ in $\mathrm{Al}$ in $\mathrm{Al}-\mathrm{Mg}$ alloys. We also point out that the insoluble constituent phases are normally coarse, and have sizes ranging from several $\mu \mathrm{m}$ to tens of $\mu \mathrm{m}$. 


\subsection{Overview of Microstructure Evolution Based on In Situ SAXS Measurements}

Figure 2 shows a typical set of reduced (background subtracted) USAXS, SAXS, and WAXS data for the AA2024 samples. Here, the SAXS and WAXS data are offset along the vertical direction for clarity. The data were acquired in situ for the SWAXS-226 sample at an isothermal ageing temperature of $226^{\circ} \mathrm{C}$. The data were measured in the sequence of USAXS, SAXS, and WAXS. The USAXS scattering intensity data were absolute calibrated using the primary calibration capability of the Bonse-Hart type USAXS instrument [56, 57]. The SAXS and WAXS data were acquired such that the 20-bit linear range (counter depth) of the Pilatus detector was optimally utilized. As part of the experiment, we carefully established limited, yet overlapping $q$ ranges between the applicable $q$ ranges of the USAXS and SAXS measurements, and of the SAXS and WAXS measurements, respectively. Using these overlapped $q$ ranges, we confirmed the validity of data merging of neighboring datasets. For the purpose of better numerical stability, we used the Irena package to numerically smear the SAXS data with the USAXS slit length prior to merging with the slit-smeared USAXS data. We used the combined USAXS and SAXS data to extract quantitative morphological information on each sample. The WAXS data were not scaled, because we were primarily interested in determining the phase identification and growth kinetics of the precipitates from these data.

Figure 3 shows the complete sets of merged USAXS and SAXS data acquired from the SWAXS190, SWAXS-208, and SWAXS-226 samples during isothermal ageing at $190{ }^{\circ} \mathrm{C}, 208{ }^{\circ} \mathrm{C}$, and $226^{\circ} \mathrm{C}$, respectively. It is clear from Figure 3 that the combined USAXS and SAXS data exhibit the following general characteristics. First, the presence of low- $q$ scattering between $1 \times 10^{-4} \AA^{-1}$ and $\approx 1 \times 10^{-3} \AA^{-1}$ indicates the presence of structural inhomogeneities at length scales that are too large to be resolved using the USAXS setup (sizes greater than $\approx 1 \mu \mathrm{m}$ ). This low- $q$ 
scattering could possibly originate from the grain structure as well as the large Fe-rich or Si-rich insoluble phases identified by TEM. More importantly, it is clear that these large structures did not change appreciably during all the artificial ageing processes, since little change was observed for the low- $q$ scattering. This lack of change in the microstructures at coarse length-scales $>1$ $\mu \mathrm{m}$ is consistent with previous findings where optical microscopy failed to reveal any microstructural changes after age hardening. [1] Moreover, in this low- $q$ regime, the desmeared differential scattering cross section $\mathrm{d} \Sigma(q) / \mathrm{d} \Omega$ (data not shown) follows a power-law form as a function of $q$ with the slope being approximately -4 . This behavior suggests that the scattering objects responsible for this scattering are roughly three-dimensional with a smooth interface.

Second, across the $q$ range between $1 \times 10^{-3} \AA^{-1}$ and $0.1 \AA^{-1}$, we observed a monotonic increase in the scattering intensity as a function of time, as highlighted by the arrows in Figure 3. This increase in intensity can be associated with a growth in the volume fraction of precipitates and possibly also in their size. The rate of increase was initially relatively rapid, but it then slowed down. The scattering intensity of the two-dimensional SAXS data showed no dependence on the azimuthal angle, indicating that the formation of the precipitates under the given experimental conditions was isotropic in nature.

Last, we observed a monotonic decay in the scattering intensity at $q$ 's higher than $0.1 \AA^{-1}$. Such behavior indicates that very small scatterers $(<1 \mathrm{~nm}$ diameter), initially present in the sample, disappeared over time, suggesting gradual dissolution of sub-nanometer scattering inhomogeneities. In order to understand the nature of this scattering entity, we performed a set of in situ TEM experiments. As an example, the inset of Figure 3(c) shows the SAED TEM data upon heating to $226^{\circ} \mathrm{C}$. The diffuse scattering, highlighted by the arrows, is a signature of the formation of very small clusters[58]. Moreover, this diffuse scattering disappears after 
approximately 2 hours of annealing at $226{ }^{\circ} \mathrm{C}$ (data not shown), consistent with the observed monotonic decay in the scattering intensity mentioned above. Earlier HRTEM and 3DAP studies by Marceau [59], Ringer [60], Sha [61], and others [62, 63] on similarly heat-treated $\mathrm{Al}-\mathrm{Cu}-\mathrm{Mg}$ alloys also point to the presence of sub-nm atomic clusters, whose formation is known as the first step in the precipitation sequence from a supersaturated solution. Based on this evidence, we made the assumption that the scattering intensity at $q$ values higher than $0.1 \AA^{-1}$ can be attributed to such clusters. These overall characteristics were observed in all three temperature series.

\subsection{Analysis of Structural Evolution from In Situ WAXS Measurements}

Figure 4(a) shows the time-dependent WAXS data from the SWAXS-226 sample under isothermal ageing at $226{ }^{\circ} \mathrm{C}$. For clarity, we opted to display one out of every five WAXS datasets in this figure. The key characteristic of the WAXS data is the growth of broad diffraction peaks, such as the one highlighted by both the arrow and the inset of Figure 4(b), which corresponds to the 112 reflection of the S phase precipitates. To quantitatively evaluate the peak profile, we performed least-squares analyses to this peak. The FWHM of this peak for the SWAXS-226 sample as a function of time is shown in Figure 4(b), where we clearly observe a decrease in the peak width as ageing progresses. This observation again suggests the growth of precipitates in AA2024 under the chosen experimental conditions.

We calculated the $d$ spacings corresponding to the peak positions identified in the WAXS data, and used these $d$ spacings to identify the phases in the AA2024 specimens. Figure 5 serves as an example to demonstrate the typical results. Here, we show the diffraction intensities as a function of $d$ spacing for the first and last sets of in situ WAXS data from sample SWAXS-226. The stick patterns correspond to calculated diffraction patterns based on known crystallographic lattice parameters and atomic positions from the International Centre for Diffraction Data database [64]. 
The peak positions are slightly shifted (by a factor of 1.004) to account for the thermal expansion at the elevated temperature used.

Figure 5 shows that most of the diffraction peaks originate from $\mathrm{CuMgAl}_{2}(\mathrm{~S}), \mathrm{Cu}_{2} \mathrm{FeAl}_{7}$, and the Al matrix (stick pattern not shown). The absence of peaks from other crystallographic phases identified in the TEM results suggests their presence only occurs at number densities or volume fractions that are below the detection limit. Also not surprisingly, we observed no diffraction peaks from the small clusters identified in either the SAXS or the WAXS data due to their very small size (hence poorly defined crystallographic structures).

The peaks related to the $\mathrm{S}$ phase and $\mathrm{Cu}_{2} \mathrm{FeAl}_{7}$ also displayed different behaviors. The S-phase peaks were initially nonexistent, but grew steadily with time. This behavior is better illustrated by the inset in Figure 4. Furthermore, the $\mathrm{S}$ phase peaks remained broad at the end of the measurements, which indicates that the size of the crystallites remains small. On the other hand, the $\mathrm{Cu}_{2} \mathrm{FeAl}_{7}$ peaks were sharp from the beginning, and also showed signs of growth while maintaining their sharpness. The sharpness of these peaks indicates the large size of the $\mathrm{Cu}_{2} \mathrm{FeAl}_{7}$ crystalline domains, which is consistent with the findings from the TEM study. These observations are consistent across our WAXS data acquired at different temperatures.

We further analyzed the growth of the diffraction peaks at different temperatures. Briefly, we focused on the growth of a single peak from a selected precipitate phase, and analyzed its peak profile to extract the peak height, peak width, and peak center across all of the WAXS data in a series. Here, for simplicity, we opted to use a modified Gaussian function to describe the peaks. We then calculated the integrated intensity, after normalization by the incident flux at the time of the measurements. This normalization was important because some of the data were acquired using the non-top-up mode of the APS [65], where the X-ray intensity varies with time. 
The results for the diffraction peak at $\approx 2.57 \AA$ are shown in Figure 6 . This peak, corresponding to the 112 reflection of the $\mathrm{S}$ precipitates, is well separated from other peaks, and it demonstrates clear growth across the temperature range. From Figure 6, it is clear that the peak growth is strongly temperature-dependent. Not surprisingly, we found that the higher the temperature, the faster the growth rate. Additionally, we note that during later stages of artificial ageing, although the integrated peak intensity increases, the peak center barely changed. The lack of change in peak center, at the same time, suggests that the crystal lattice parameters were stable. The FWHM of this peak, as shown earlier in Figure 4(b), decreases as a function of time, which implies that the precipitate is indeed growing. We conclude that the change in the integrated diffraction intensity and the peak width from the $\mathrm{S}$ phase peaks could be attributed to the nucleation and growth of the precipitates.

\subsection{Quantitative Microstructure Model}

We analyzed the combined USAXS and SAXS data series using the small-angle scattering analysis software suite, Irena, in the Igor Pro environment [66]. In our analysis, we adopted a minimalist approach in constructing our scattering models, i.e., we limited the number of fitting parameters to the lowest possible while requiring the model be consistent with the physical nature of the underlying system. An illustration of our microstructure model is shown in Figure 7. For this model, we have three major assumptions. First, the increase in scattering intensity between $1 \times 10^{-3} \AA^{-1}$ and $0.1 \AA^{-1}$ is attributed to the nucleation and growth of plate-shaped $\mathrm{S}$ phase precipitates with long dimensions (diameter) fixed at $200 \mathrm{~nm}$ and a varying short dimension (thickness) which follows a Lifshitz-Slyozov-Wagner (LSW) size distribution [67]. Second, the decrease in scattering intensity at $q$ 's higher than $0.1 \AA^{-1}$ is attributed to the dissolution of small spherical clusters (GPB zones) with fixed radius. Third, the entire dataset 
collected at a given temperature shares a common scattering-intensity baseline, i.e., the intensity increase due to the plate-like precipitates and the intensity-decrease due to dissolution of small spherical clusters are on top of a fixed baseline that does not change appreciably with time. We will examine each of these three assumptions below.

Using dark-field TEM, we examined the morphology of the S phase precipitates along several different crystallographic orientations, including (131), (11-1), (-11-1), (-202), and (220) directions. Along each orientation, the $\mathrm{S}$ precipitates' projections are needle-shaped with a nominal length of approximately $200 \mathrm{~nm}$. From a geometrical point of view, needle-shaped projections along different orientations form strong evidence that $\mathrm{S}$ precipitates are 2D planar objects, i.e., disks. This conclusion is consistent with previous reports where S precipitates were identified as platelet-shaped. $[9,20,68]$ The disk thickness has a dimension of $<10 \mathrm{~nm}$, as illustrated in Figure 1. We assumed that this thickness follows a LSW size distribution, which describes the changes of thermodynamically-driven inhomogeneous precipitate structure over time. [69] In addition, USAXS analysis shows that precipitates that are needle shaped, spherical, or disk shaped with diameters greatly different from $200 \mathrm{~nm}$ are inconsistent with the scattering data. This forms the basis of the first assumption.

The USAXS/SAXS scattering intensity in the $q$ range higher than $0.2 \AA^{-1}$ strongly indicates the presence of sub-nm scale scattering inhomogeneities. Within the framework of the existing literature and our model, we attribute this intensity as scattering from very small (sub-nm) clusters. Due to the small nominal size of these clusters, their contribution to the total scattering intensity is not significant. We opted not to discriminate the changes in cluster size and cluster volume simultaneously. Instead, in order to monitor the dissolution kinetics, we assumed that the 
clusters are spherical and their size distribution does not change with time. In other words, only volume is changing. This forms the basis for the second assumption.

The assumption of a scattering baseline is manifested by the overall behavior of the data shown in Figure 3. While we do not attempt to delineate the origin of this scattering baseline, we note that with the number of constituent phases identified from the TEM results and the recognition that these samples are off-the-shelf, mass-produced alloys, it is reasonable to assume stable microstructural component(s) exist at the chosen ageing temperatures that also contribute to the scattering curves in the observed $q$ range, hence the third assumption.

Using these assumptions, we arrived at a 3-parameter model, with the parameters being the volume of the small clusters, the volume of the precipitates, and the nominal thickness of the precipitates. While this model is simple, we believe that it captures the major elements of physical precipitation and dissolution events in AA2024 for the reasons stated above, and it is consistent with existing literature on the precipitation sequence of $\mathrm{Al}-\mathrm{Cu}-\mathrm{Mg}$ alloys. To demonstrate this model, we show two datasets acquired at $208{ }^{\circ} \mathrm{C}$ in Figure 7(a). Here, the nominal radius of the small clusters was set to $0.41 \mathrm{~nm}$, which is in qualitative agreement with the size of 24-atom cluster found in the early stage of commercial AA2024 at $170{ }^{\circ} \mathrm{C}$.[61] The data acquired at 12 min and 492 min were the first and last data sets acquired at this temperature, respectively. In both cases, we found that this simple model describes the data satisfactorily. Most notably, when comparing the $492 \mathrm{~min}$ data with the $12 \mathrm{~min}$ data, the modelled precipitate scattering intensity not only accounts for the relatively large intensity increase between $0.01 \AA^{-1}$ and $0.1 \AA^{-1}$, but also the relatively small intensity increase near $0.002 \AA^{-1}$. This observation presents additional evidence for the validity of the plate-like morphology of the S precipitates. Furthermore, we show the scattering data acquired at 72 min into the in situ ageing treatment at 
$208{ }^{\circ} \mathrm{C}$ and its associated model components in Figure 7(b). This intermediate dataset shows the simultaneous contributions from the baseline, clusters, and the $\mathrm{S}$ phase precipitates to the acquired scattering intensity. We'd like to point out that Figure 7 also exemplifies an important characteristic of small-angle scattering of precipitates in metallic systems. In these systems, precipitates are often only partially responsible for the observed scattering intensity profiles. A scattering baseline, which could originate from many sources including parasitic scattering, scattering from large structures, structural defects and constituent phases, should be accounted for whenever possible. Otherwise, SAS analysis risks erroneous results. Without a sufficiently broad $q$ range, this low- $q$ behavior and the scattering baseline are difficult to establish with precision [29]. However, we assert that, with our combined approach, this issue is well taken care of from a metrological point of view.

\subsection{Model Results and Interpretation for SAXS Data}

Using the above model, we analyzed the scattering profiles in the data series acquired with isothermal ageing treatments at $190{ }^{\circ} \mathrm{C}, 208^{\circ} \mathrm{C}$, and $226{ }^{\circ} \mathrm{C}$. Using a custom-made least-squares fitting routine within the framework of Irena, we sought for the fitting parameters that best account for the growth of the precipitates and the dissolution of the clusters. The results, including the evolution of the nominal thickness and the total scattering volumes of both the precipitates and the clusters are shown in Figure 8 . As one would expect, Figure 8 shows that the continuous growth of the precipitates is temperature-dependent. It follows the general trend that the higher the temperature, the faster the precipitate growth process. The size of the precipitates also appears to be temperature-dependent with a lower temperature leading to a smaller nominal LSW thickness of the precipitates, and thus, smaller precipitates. At the end of the series, the thickness of the precipitate plates was between $3 \mathrm{~nm}$ and $6 \mathrm{~nm}$. These values and the 
development of the thickness as functions of time agree well with our ex situ TEM findings, and also qualitatively agree with results found in a recent in situ artificial ageing experiment of plastically deformed 7075 aluminum alloy.[70]

While the volume fraction of the precipitates increases monotonically with time, the volume fraction of the small clusters, on the other hand, decreases monotonically as shown in Figure 8(c). We modeled the evolution of the cluster scattering volume fraction using a simple function $V=$ $V_{0}+C \times \exp (-\kappa \times t)$, where $t$ is time and $\kappa$ is a temperature-dependent kinetic rate. The fitting results are shown in Table 5. An Arrhenius plot based on the fitted rates is shown in Figure 9. We found the activation energy responsible for the dissolution of the small clusters in AA2024 to be $(149.5 \pm 14.6) \mathrm{kJ} \mathrm{mol}^{-1}$, which translates to $(1.55 \pm 0.15) \mathrm{eV} /$ atom. We note that this activation energy was acquired using the assumption in the SAXS analysis that the sub-nm cluster size is fixed. Given the very small size of the clusters, this assumption may serve as a realistic approximation to the physical reality. Yet, we emphasize that it is still an assumption. We also note that our acquired dissolution energy based on this assumption is similar to the values identified for the GPB zones in various aluminum alloys $[16,71,72]$.

Our modeling approach was successful, overall. However, as shown in Figure 8(a) and (b), it fails to capture the development of the S precipitates in the very early stage of the SWAXS-190 sample series. This is due to the fact that the scattering baseline is significant in the relevant $q$ range where the scattering intensity of $\mathrm{S}$ precipitates emerges. When the amount of the $\mathrm{S}$ precipitates is very small $(<1 \%$ by volume), its contribution to the overall scattering intensity cannot be conclusively determined due to the instrumental measurement uncertainty. At the same time, correct determination of the functional form of the precipitation kinetics and the subsequent determination of the activation energy requires the volume fraction of the $S$ phase precipitates 
during the early stage of isothermal ageing at $190{ }^{\circ} \mathrm{C}$. The cluster scattering, on the other hand, is well above the scattering baseline (background) and therefore not subject to this limitation. To unequivocally determine the growth kinetics of the S precipitates across all temperature series, we made use of the scattering invariant as an alternative, model-independent way of evaluating the scattering volume.

For an incompressible two-phase system, the scattering invariant is defined as

$$
Q=\int_{0}^{\infty} q^{2} \times I(q) d q=2 \pi^{2} V_{p}\left(1-V_{p}\right) \Delta \rho^{2},
$$

where $V_{p}$ is the volume fraction of the precipitates, and $\Delta \rho^{2}$ is the scattering contrast in absolute terms. In theory, this analysis allows the calculation of the volume fraction of each component in a two-phase system when the contrast is known. However, in practice, this analysis is often difficult due to the challenges in measuring the scattering intensity over a sufficiently wide $q$ range to make the calculation of the scattering invariant reliable. For this analysis, the 4 decades in $q$ afforded by the combined USAXS and SAXS measurements is clearly beneficial. Additionally, in order for Eqn. (1) to be valid, the scattering intensity $I(q)$ must be absolutecalibrated, which is provided by the USAXS instrument as described in the Materials and Methods section. A last requirement for Eqn. (1) is the isotropy of the scattering intensity, which was established by the fact that the 2D SAXS scattering intensities from all samples are circularly symmetric around the incident beam direction.

To prepare the scattering intensity input $\mathrm{I}(\mathrm{q})$ for Eqn. (1), we first made use of the Lake desmearing algorithm [73] to convert the slit-smeared scattering cross section to a differential scattering cross section. To calculate the scattering invariant from the S precipitates, we started by calculating the overall scattering invariant for the combined USAXS and SAXS data. We then numerically calculated the contribution to the total scattering invariant from the small clusters as 
determined from the aforementioned modeling approach. After subtracting the cluster contribution, we further removed the constant contribution from the scattering baseline to arrive at the scattering invariant that is attributed to the growth of the $\mathrm{S}$ precipitates.

With these considerations, we calculated the scattering invariants for the small angle scattering profiles over their measured $q$ ranges. We then calculated the absolute scattering volume of the $\mathrm{S}$ precipitates, making use of both Eqn. (1) and the scattering contrasts shown in Table 4. Figure 10(a) shows the scattering invariant as a function of time for all three ageing series. We found that these data are in good agreement with the scattering volume fractions attained through leastsquares modeling. This agreement serves to confirm the validity of both sets of results. We modelled the development of the scattering invariant as a function of time following a simple function $V=V_{0}-C \times \exp (-\kappa \times t)$, where $t$ is time, $\kappa$ is a temperature-dependent rate, and $V_{0}$ is the asymptotic term as $t \rightarrow \infty$. The fitting results are shown in Table 6 . We then used the temperature-dependent $\kappa$ and performed an Arrhenius analysis, which is shown in Figure 10(b). Through this analysis, we identified the activation energy responsible for the formation and growth of S precipitates in AA2024 to be $(129.2 \pm 5.4) \mathrm{kJ} \mathrm{mol}^{-1}$, i.e. $(1.33 \pm 0.06) \mathrm{eV} /$ atom. Theoretically, this activation energy is related to the diffusion barrier as modeled in the homogeneous nucleation process in pseudo-binary alloys. [74, 75] Our measured activation energy is fully consistent with the activation energy $\left(133 \pm 6 \mathrm{~kJ} \mathrm{~mol}^{-1}\right)$ acquired from DSC experiments[76, 77] as well as the model-predicted value $135 \mathrm{~kJ} \mathrm{~mol}^{-1}$ [77]. This agreement provides a further indication of the soundness of our modeling approach. Moreover, the $V_{0}$ parameter serves as an indicator of the maximum total volume fraction that the precipitates could attain if this kinetic growth mechanism is followed to completion. We found that $V_{0}$ decreases 
with increasing temperature, as shown in Figure 10(c), which suggests that a longer precipitation process at a lower temperature is beneficial for the growth of $\mathrm{S}$ precipitates.

\subsection{Further Discussion and Numerical Modeling}

These in situ combined USAXS/SAXS/WAXS studies lead to a further important conclusion. Under the constraint of the detection limit provided by the X-ray scattering/diffraction instrument that was used, the controversial intermediate GPB2/S" phase was not found in the precipitation sequence of these AA2024 materials. Such GPB2/S" phase precipitates were previously suggested to be $\approx 10 \mathrm{~nm}$ in diameter [9], a size that is clearly within the detectable size range of combined USAXS/SAXS. Unlike the small GPB zones that form within minutes after ageing temperature is reached [78], a small number of GPB2/ S" phase precipitates were thought to survive even after over 40 hours at ageing temperature $>170{ }^{\circ} \mathrm{C}$ [9]. The $\mathrm{SAXS}$ data analysis method that we adopted, however, ruled out the existence of this intermediate phase. Additionally, as previously suggested, the GPB2/S" phase has the composition of $\mathrm{Al}_{10} \mathrm{Cu}_{3} \mathrm{Mg}_{3}$ and an orthorhombic structure (space group Imm2) with lattice parameters $\mathrm{a}=0.405 \mathrm{~nm}, \mathrm{~b}=$ $1.62 \mathrm{~nm}$ and $\mathrm{c}=0.405 \mathrm{~nm}$, respectively [79]. Diffraction peaks that belong to such a structure were also missing in the in situ WAXS data. Given this evidence, we conclude that at least in these specific AA2024 samples, we do not identify an intermediate GPB2/S" phase.

It is also thought that the formation of the $\mathrm{S}$ phase does not involve a transformation from any precursors [80]. While our results do not present any evidence for or against this argument, we do note that the dissolution of the GPB zones and the formation of the S phase occur simultaneously with the cluster-dissolution rate approximately double that of the S-phase formation. It will require further experimental or theoretical efforts to test whether these two processes are inherently linked. 
To better predict and interpret the observed precipitation kinetics, we performed numerical modeling based on the Kampmann and Wagner (KW) type numerical analysis for the precipitation process. Precipitate-composition wise, the equilibrium phase fractions as a function of temperature are shown in Figure 11. For the ageing temperatures of interest, the predicted equilibrium phases include the $\mathrm{Al}_{2} \mathrm{Cu}, \mathrm{S}, \mathrm{Al}_{15} \mathrm{Si}_{2}(\mathrm{Fe}, \mathrm{Mn})_{4}$ (also referred to as solution phase $t$ ), $\mathrm{Al}_{7} \mathrm{Cu}_{2} \mathrm{Fe}$ and $\mathrm{MgSi}_{2}$. This prediction agrees remarkably well with our TEM observations. Other than $\mathrm{Al}_{15} \mathrm{Si}_{2}(\mathrm{Fe}, \mathrm{Mn})_{4}$ (we observed $\left.\mathrm{Al}_{12}(\mathrm{Fe}, \mathrm{Mn})_{3} \mathrm{Si}\right)$, all of the predicted phases were identified. To model the precipitation occurring in the alloy, a set of conditions needs to be set correctly. We assumed that the matrix phase was the $\mathrm{FCC}$ phase and $\mathrm{Al}_{2} \mathrm{Cu}$ and $\mathrm{S}$ phases are possible precipitates. Other equilibrium precipitates, $\mathrm{Al}_{15} \mathrm{Si}_{2}(\mathrm{Fe}, \mathrm{Mn})_{4}, \mathrm{Al}_{7} \mathrm{Cu}_{2} \mathrm{Fe}$, and $\mathrm{MgSi}_{2}$ were initially considered in the simulation but did not appear during the simulated precipitation. The minimum radius for the nucleus of a precipitating particle was assumed to be $0.5 \mathrm{~nm}$. The precipitation was modeled at the ageing temperatures of $190{ }^{\circ} \mathrm{C}, 208^{\circ} \mathrm{C}$, and $226^{\circ} \mathrm{C}$, respectively. We assumed an average grain size of the FCC phase of $100 \mathrm{~mm}$ and an average grain aspect ratio of 1. Bulk nucleation was assumed to dominate with the number of nucleation sites set at $8.6 \times 10^{27}$. We set the bulk interfacial energies for the $\mathrm{S}$ phase and the $\mathrm{Al}_{2} \mathrm{Cu}$ phase at $35 \mathrm{~mJ} / \mathrm{m}^{3}$. For simplicity, the precipitates were assumed to be spherical and to have a uniform composition based on a local equilibrium calculation. The molar volumes of the phases were assumed to be $1.0 \times 10^{-5} \mathrm{~m}^{3} / \mathrm{mol}$. Figure 12 shows the predicted volume fraction of $\mathrm{S}$ phase as a function of time for the three different ageing temperatures. The precipitation behavior is similar at all three temperatures. This is most easily seen when the results are plotted on a log-based time scale, as seen Figure 12 (b). Initially, the nucleation dominates the precipitation process and the volume fraction does not increase. In the nucleation stage, the volume fraction is well below $0.1 \%$, a regime where the 
signal-to-noise ratio in our SAXS experiments does not allow an accurate determination of the scattering volume. The growth regime is indicated by the rapid increase in the volume fraction. At $226{ }^{\circ} \mathrm{C}$, the growth process occurs between 10 minutes and 35 minutes and at $220{ }^{\circ} \mathrm{C}$ the growth process occurs between 45 minutes and 120 minutes. At $190{ }^{\circ} \mathrm{C}$, the nucleation process is much longer and the growth process does not become dominant until 300 minutes and then continues for an additional 500 minutes. The simulations qualitatively agree with the experimental results (Figure 8) as both the experiments and simulations show that the nucleation stage is short for $226^{\circ} \mathrm{C}$ and $208^{\circ} \mathrm{C}$, and there is a rapid increase in the volume fraction during the growth process. In Figure 8, the growth process dominates from approximately 10 minutes to 200 minutes at $226{ }^{\circ} \mathrm{C}$ and from approximately 10 minutes to 350 minutes at $208{ }^{\circ} \mathrm{C}$. A longer growth dominate region at $190{ }^{\circ} \mathrm{C}$ is observed in both experiments and simulations. While the experiments were not able to indicate the transition from the nucleation to growth dominated regimes, the experiments clearly show the volume fraction continues to increase from 200 minutes to 800 minutes.

The experiments indicate the that the equilibrium volume fraction increases with decreasing temperature, in agreement with the equilibrium phase fractions predicted in Figure 11 that show a small increase in the equilibrium phase fraction of the $\mathrm{S}$ phase with decreasing temperature. The simulations show that, during the coarsening regime, the equilibrium volume fraction is approached. Close examination of the simulation values also shows that as the temperature decreases, the equilibrium volume fraction increases; however, the increase is extremely small compared with the experimental observations. The equilibrium values at the annealing temperatures are the following: at $226{ }^{\circ} \mathrm{C}$ it is $0.0727,208{ }^{\circ} \mathrm{C}$ it is 0.0731 , and at $190{ }^{\circ} \mathrm{C}$ it is 0.0733. The predicted time at which the $\mathrm{S}$ phase volume fraction at $208{ }^{\circ} \mathrm{C}$ exceeds the $226{ }^{\circ} \mathrm{C}$ 
volume fraction occurs at approximately 700 minutes. This cross-over time is approximately double what is observed experimentally. At $190{ }^{\circ} \mathrm{C}$, the predicted time when the volume fraction exceeds those at 226 and $208{ }^{\circ} \mathrm{C}$ is approximately 1200 minutes (not shown in Figure 12). Again, this cross-over time is almost double what is observed experimentally. It should also be noted that the predicted equilibrium volume fraction at $226{ }^{\circ} \mathrm{C}$ is in good agreement with the experimental extrapolations seen in Figure 10(c). However, the simulations do not predict as large a decrease in the equilibrium volume fractions at $208^{\circ} \mathrm{C}$ and $190{ }^{\circ} \mathrm{C}$.

We note that there are discrepancies between the model predictions and experimental findings, including the equilibrium volume fractions and the time scales for the nucleation dominated regime. Many factors could contribute to this quantitative difference, but the assumed spherical geometry of the precipitates is the most likely candidate. The larger surface-to-volume ratio of platelet-shaped precipitates during later stages of growth allows faster incorporation of diffusing solute atoms into the precipitate than an assumption of spherical precipitates would predict. Other factors that could affect the quantitative agreement between theory and experiment include the assumed grain size and shape, dislocation density, and the temperature-dependence of the interfacial energy [77]. From the experimental side, we calculated the scattering length densities based on perfect crystallographic data from the crystallographic database. In a real isothermal ageing experiment, these scattering length densities will be slightly off from the theoretical values, which in turn would result in a slightly different experimental volume fraction. Notwithstanding these reservations, we identified an excellent correspondence between the measured and predicted S-phase precipitation kinetics and final equilibrium phase diagrams.

\section{Conclusions}


The performance of AA2024, one of the most widely used structural materials in the aerospace industry, is closely tied to the precipitation hardening process. For this process, a direct structural understanding of the precipitation kinetics under realistic artificial ageing conditions is needed. In this paper, we presented a combined experimental and modeling study to address this need. Using ex situ TEM, we identified the existence of multiple precipitate and constituent phases, their morphologies, sizes, and atomic structures. Using in situ combined USAXS/SAXS/WAXS measurements, we characterized the time-dependent structure and morphology of the precipitates across a length scale range from sub-Angstrom to several micrometers, under three different artificial ageing conditions. The in situ WAXS results clearly showed the emergence of the S-phase precipitates as a function of time, while diffraction fingerprints of the small clusters were absent. A detailed analysis of the integrated intensity of the precipitate peaks showed precipitation kinetics very similar to that identified from the USAXS/SAXS analysis.

Based on the TEM findings, we constructed a simple three-parameter model for the combined USAXS/SAXS data. This model enabled extraction of the detailed kinetic behaviors of the dissolution process of nanometer-sized small clusters and the formation process of the much larger planar S-phase precipitates, including the size, shape, and volume fraction of the precipitates. We found that, while these two processes occurred simultaneously, the cluster dissolution happened at a rate approximately double that of the S-phase formation. We also extracted the dissolution activation energy of $(149.5 \pm 14.6) \mathrm{kJ} \mathrm{mol}^{-1}$ and the activation energy for the formation of $\mathrm{S}$ precipitates of $(129.2 \pm 5.4) \mathrm{kJ} \mathrm{mol}^{-1}$. Both values are in good agreement with activation energies previously found by other techniques.

We performed a computational-thermodynamics-based modeling analysis to predict and validate the precipitation kinetics using TC-PRISMA software package. This analysis predicted the equilibrium phase diagram as a function of temperature, as well as the evolution of the volume fraction of the $\mathrm{S}$ phase as a function of time at three ageing temperatures. The equilibrium phase 
diagram predicted phases that were identified by TEM. The modeling also revealed two general trends. 1. At any given fixed time, higher temperature always leads to a large volume of the $\mathrm{S}$ precipitates. 2. The equilibrium volume of the $\mathrm{S}$ phase precipitates is higher at lower temperature. In general, there is a good agreement between the modeling predictions and the experimental results.

Notably, ex situ TEM and in situ synchrotron SAXS and WAXS results showed an absence of fingerprints of the often-debated GPB2/ S" phase, which suggests that at least in these samples under the experimental ageing conditions, the GPB2/ S" phase may not be part of the transformational sequence.

From a technique point of view, this study of the precipitation kinetics has proven the need of using complimentary methods such as TEM and SAXS for the experimental characterization of the precipitates. More importantly, we established the importance of obtaining a good scattering baseline for an accurate analysis of precipitate morphology and growth. For constructing a scattering baseline, as well as capturing the possible simultaneous multiple-component kinetics occurring at different length scales (for instance, dissolution kinetics and $\mathrm{S}$ phase formation kinetics in this case), a large scattering size range is required. For this reason, we believe that the method that we developed, i.e., the combination of USAXS/SAXS/WAXS, offers a unique opportunity to simultaneously characterize precipitation kinetics and provide phase identification. When coupled with realistic sample environments and multiplexing measurement schemes [81], it has the potential to open a new paradigm for in operando investigations of industrially important structural alloys and other advanced functional materials, such as gradient nanostructure materials [82] and dual-anneal diffusion multiple materials [83]. 


\section{Acknowledgement:}

ChemMatCARS Sector 15 is principally supported by the Divisions of Chemistry (CHE) and Materials Research (DMR), National Science Foundation, under grant number NSF/CHE1346572. Use of the Advanced Photon Source, an Office of Science User Facility operated for the U.S. Department of Energy (DOE) Office of Science by Argonne National Laboratory, was supported by the U.S. DOE under Contract No. DE-AC02-06CH11357. 


\section{References:}

[1] I. Polmear. Aluminium Alloys--A Century of Age Hardening. Mater. Forum, vol. 28, 2004. p.1-

14.

[2] S. Wang, M. Starink. Precipitates and intermetallic phases in precipitation hardening $\mathrm{Al}-\mathrm{Cu}-\mathrm{Mg}-$ (Li) based alloys, Int. Mater. Rev. 50 (2005) 193-215.

[3] P. Schmutz, G. Frankel. Corrosion Study of AA2024-T3 by Scanning Kelvin Probe Force Microscopy and In Situ Atomic Force Microscopy Scratching, J. Electrochem. Soc. 145 (1998) 22952306.

[4] C. Genevois, A. Deschamps, A. Denquin, B. Doisneau-Cottignies. Quantitative investigation of precipitation and mechanical behaviour for AA2024 friction stir welds, Acta Mater. 53 (2005) 2447-2458.

[5] Y. Li, L. Murr, J. McClure. Flow visualization and residual microstructures associated with the friction-stir welding of 2024 aluminum to 6061 aluminum, Mater. Sci. Eng., A 271 (1999) 213-223.

[6] M. Easton, D. Stjohn. Grain refinement of aluminum alloys: Part I. The nucleant and solute paradigms - a review of the literature, Metall. Mater. Trans. A 30 (1999) 1613-1623.

[7] S. Singh, D. Goel. Influence of thermomechanical aging on fatigue behaviour of 2014 Al-alloy, Bull. Mater. Sci. 28 (2005) 91-96.

[8] M. Gao, C. Feng, R.P. Wei. An analytical electron microscopy study of constituent particles in commercial 7075-T6 and 2024-T3 alloys, Metall. Mater. Trans. A 29 (1998) 1145-1151.

[9] H.-C. Shih, N.-J. Ho, J. Huang. Precipitation behaviors in Al-Cu-Mg and 2024 aluminum alloys, Metall. Mater. Trans. A 27 (1996) 2479-2494.

[10] L. Kovarik, M. Miller, S. Court, M. Mills. Origin of the modified orientation relationship for S (S ")-phase in Al-Mg-Cu alloys, Acta Mater. 54 (2006) 1731-1740.

[11] S. Ringer, K. Hono, I. Polmear, T. Sakurai. Nucleation of precipitates in aged $\mathrm{Al} \mathrm{Cu} \mathrm{Mg} \mathrm{(Ag)}$ alloys with high Cu: Mg ratios, Acta Mater. 44 (1996) 1883-1898.

[12] Y. Lin, Y.-C. Xia, Y.-Q. Jiang, H.-M. Zhou, L.-T. Li. Precipitation hardening of 2024-T3 aluminum alloy during creep aging, Mater. Sci. Eng., A 565 (2013) 420-429.

[13] M. Rosen, L. Ives, S. Ridder, F. Biancaniello, R. Mehrabian. Correlation between ultrasonic and hardness measurements in aged aluminum alloy 2024, Mater. Sci. Eng. 74 (1985) 1-10.

[14] R. Horiuchi, Y. Minonishi. AGEING BEHAVIOUR OF AN AL-CU-MG ALLOY, J JAPAN INST METALS 34 (1970) 936-943.

[15] M. Rosen, E. Horowitz, L. Swartzendruber, S. Fick, R. Mehrabian. The aging process in aluminum alloy 2024 studied by means of eddy currents, Mater. Sci. Eng. 53 (1982) 191-198.

[16] A. Jena, A. Gupta, M. Chaturvedi. A differential scanning calorimetric investigation of precipitation kinetics in the Al-1.53 wt\% Cu-0.79 wt\% Mg alloy, Acta Metall. 37 (1989) 885-895.

[17] Y. Bagaryatsky. Charateristics of Natural Aging of Aluminum Alloy. Dokl Akad SSSR, vol. 87, 1952. p.559.

[18] A. Charai, T. Walther, C. Alfonso, A.-M. Zahra, C. Zahra. Coexistence of clusters, GPB zones, S "-, S'-and S-phases in an Al-0.9\% Cu-1.4\% Mg alloy, Acta Mater. 48 (2000) 2751-2764.

[19] Y.A. Bagaryatsky. Structural changes on aging Al-Cu-Mg alloys, Doklady Akademii Nauk, SSSR 87 (1952) 397-562.

[20] S. Wang, M. Starink. Two types of S phase precipitates in $\mathrm{Al}-\mathrm{Cu}-\mathrm{Mg}$ alloys, Acta Mater. 55 (2007) 933-941.

[21] S. Ringer, K. Hono, I. Polmear, T. Sakurai. Nucleation of precipitates in aged AlCuMg (Ag) alloys with high Cu: Mg ratios, Acta Mater. 44 (1996) 1883-1898.

[22] M. Starink*, N. Gao, L. Davin, J. Yan, A. Cerezo. Room temperature precipitation in quenched $\mathrm{Al}-\mathrm{Cu}-\mathrm{Mg}$ alloys: a model for the reaction kinetics and yield strength development, Philos. Mag. 85 (2005) 1395-1417.

[23] A. Deschamps, F. Livet, Y. Brechet. Influence of predeformation on ageing in an $\mathrm{Al}-\mathrm{Zn}-\mathrm{Mg}$ alloy-I. Microstructure evolution and mechanical properties, Acta Mater. 47 (1998) 281-292. 
[24] C. Antion, P. Donnadieu, F. Perrard, A. Deschamps, C. Tassin, A. Pisch. Hardening precipitation in a Mg-4Y-3RE alloy, Acta Mater. 51 (2003) 5335-5348.

[25] Y. Idell, L. Levine, A. Allen, F. Zhang, C. Campbell, G. Olson, J. Gong, D. Snyder, H. Deutchman. Unexpected $\delta$-Phase Formation in Additive-Manufactured Ni-Based Superalloy, JOM 68 (2016) 950-959.

[26] S. Imhoff, J. Ilavsky, F. Zhang, P. Jemian, P. Evans, J. Perepezko. Kinetic transition in the growth of Al nanocrystals in Al-Sm alloys, Journal of Applied Physics 111 (2012) 063525.

[27] A. Guinier. Structure of age-hardened aluminium-copper alloys, Nature 142 (1938) 569-570.

[28] A. Guinier, G. Fournet, C.B. Walker, K.L. Yudowitch. Small-angle scattering of X-rays, (1955).

[29] A. Deschamps, F. De Geuser. Quantitative Characterization of Precipitate Microstructures in Metallic Alloys Using Small-Angle Scattering, Metall. Mater. Trans. A 44 (2013) 77-86.

[30] M. Sutton, B. Yang, A. Reynolds, R. Taylor. Microstructural studies of friction stir welds in 2024-T3 aluminum, Mater. Sci. Eng., A 323 (2002) 160-166.

[31] B. Yang, J. Yan, M.A. Sutton, A.P. Reynolds. Banded microstructure in AA2024-T351 and AA2524-T351 aluminum friction stir welds: Part I. Metallurgical studies, Mater. Sci. Eng., A 364 (2004) 55-65.

[32] P. Campestrini, E. Van Westing, H. Van Rooijen, J. De Wit. Relation between microstructural aspects of AA2024 and its corrosion behaviour investigated using AFM scanning potential technique, Corros. Sci. 42 (2000) 1853-1861.

[33] D. Franke, C.M. Jeffries, D.I. Svergun. Correlation Map, a goodness-of-fit test for onedimensional X-ray scattering spectra, Nature methods 12 (2015) 419-422.

[34] J. Ilavsky, P.R. Jemian, A.J. Allen, F. Zhang, L.E. Levine, G.G. Long. Ultra-small-angle X-ray scattering at the Advanced Photon Source, Journal of Applied Crystallography 42 (2009) 469-479.

[35] J. Ilavsky, A.J. Allen, L.E. Levine, F. Zhang, P.R. Jemian, G.G. Long. High-energy ultra-smallangle X-ray scattering instrument at the advanced photon source, Journal of Applied Crystallography 45 (2012) 1318-1320.

[36] E. Eikenberry, C. Brönnimann, G. Hülsen, H. Toyokawa, R. Horisberger, B. Schmitt, C. SchulzeBriese, T. Tomizaki. PILATUS: a two-dimensional X-ray detector for macromolecular crystallography, Nucl. Instrum. Methods Phys. Res., Sect. A 501 (2003) 260-266.

[37] J. Ilavsky, F. Zhang, A. Allen, L. Levine, P. Jemian, G. Long. Ultra-small-angle X-ray scattering instrument at the advanced photon source: history, recent development, and current status, Metallurgical and Materials Transactions A 44 (2013) 68-76.

[38] D.R. Black, D. Windover, A. Henins, D. Gil, J. Filliben, J.P. Cline. Certification of NIST standard reference material 640d, Powder Diffr. 25 (2010) 187-190.

[39] D.R. Black, D. Windover, A. Henins, J. Filliben, J.P. Cline. Certification of standard reference material 660B, Powder Diffr. 26 (2011) 155-158.

[40] S. Cheng, Y. Zhao, Y. Zhu, E. Ma. Optimizing the strength and ductility of fine structured 2024 $\mathrm{Al}$ alloy by nano-precipitation, Acta Mater. 55 (2007) 5822-5832.

[41] L. Wang, H. Flower, T. Lindley. Precipitation of the $\omega$ phase in 2024 and 2124 aluminium alloys, Scripta Mater. 41 (1999) 391-396.

[42] Heat Treating of Aluminum Alloys. ASM Handbook, vol. 4, Heat Treating. ASM International, 1990. pp. $841-879$.

[43] TC-PRISMA version 2.0.3. Thermo-Calc Software AB, Stockholm, Sweden. 2013.

[44] P.F. Shi, A. Engström, B. Sundman, J. Ågren. Thermodynamic calculations and kinetic simulations of some advanced materials. Mater. Sci. Forum, vol. 675: Trans Tech Publ, 2011. p.961-974.

[45] Q. Chen, K. Wu, G. Sterner, P. Mason. Modeling Precipitation Kinetics During Heat Treatment with Calphad-Based Tools, J. Mater. Eng. Perform. 23 (2014) 4193-4196.

[46] J. Langer, k. Schwartz. Kinetics of nucleation in near-critical fluids, Phys. Rev. A 21 (1980) 948.

[47] R. Kampmann, R. Wagner. Decomposition of alloys: the early stages. Proc. 2nd Acta-Scripta

Metall. Conf., Pergamon, Oxford, 1984. p.91-103. 
[48] R. Wagner, R. Kampmann, P.W. Voorhees. Homogeneous Second-Phase Precipitation, Mater. Sci. Technol. (1991).

[49] S. Thermo-Calc Software AB, Sweden. . TCS Aluminium-based Alloy Thermodynanic Databases TCAL, version 4., 2015.

[50] S. Thermo-Calc Software AB, Sweden. TCS Al-alloys Mobility Database, MOBAL, version 3. 2013.

[51] ASTM. Analytical chemistry for metals, ores, and related materials, ASTM International, 2014.

[52] P. Villars, A. Prince, H. Okamoto. Handbook of ternary alloy phase diagrams, ASM international, 1995.

[53] E. Starke Jr, J. Staley. Application of modern aluminum alloys to aircraft, Progress in Aerospace Sciences 32 (1996) 131-172.

[54] S. WANG, C. LI, M. Y AN, W. BIAN. Microstructure study of constituent phases in 2024 series Al alloys, Acta Metallurgica Sinica 3 (1990) 104-109.

[55] H.P.E.A. WESTGREN. The crystal structure of Al2CuMg, Arkiv Kemi Mineral Geol 16B 13 (1943).

[56] G. Long, P. Jemian, J. Weertman, D. Black, H. Burdette, R. Spal. High-resolution small-angle Xray scattering camera for anomalous scattering, J. Appl. Crystallogr. 24 (1991) 30-37.

[57] F. Zhang, J. Ilavsky, G.G. Long, J.P. Quintana, A.J. Allen, P.R. Jemian. Glassy carbon as an absolute intensity calibration standard for small-angle scattering, Metall. Mater. Trans. A 41 (2010) 11511158.

[58] L. Berg, J. Gjønnes, V. Hansen, X. Li, M. Knutson-Wedel, G. Waterloo, D. Schryvers, L. Wallenberg. GP-zones in Al-Zn-Mg alloys and their role in artificial aging, Acta Mater. 49 (2001) 34433451 .

[59] R. Marceau, G. Sha, R. Lumley, S. Ringer. Evolution of solute clustering in $\mathrm{Al}-\mathrm{Cu}-\mathrm{Mg}$ alloys during secondary ageing, Acta Mater. 58 (2010) 1795-1805.

[60] S. Ringer, K. Hono. Microstructural evolution and age hardening in aluminium alloys: Atom probe field-ion microscopy and transmission electron microscopy studies, Mater. Charact. 44 (2000) 101131.

[61] G. Sha, R. Marceau, X. Gao, B. Muddle, S. Ringer. Nanostructure of aluminium alloy 2024: Segregation, clustering and precipitation processes, Acta Mater. 59 (2011) 1659-1670.

[62] S. Abis, M. Massazza, P. Mengucci, G. Riontino. Early ageing mechanisms in a high-copper AlCuMg alloy, Scripta Mater. 45 (2001) 685-691.

[63] A. Biswas, D.J. Siegel, C. Wolverton, D.N. Seidman. Precipitates in Al-Cu alloys revisited: Atom-probe tomographic experiments and first-principles calculations of compositional evolution and interfacial segregation, Acta Mater. 59 (2011) 6187-6204.

[64] A. Belsky, M. Hellenbrandt, V.L. Karen, P. Luksch. New developments in the Inorganic Crystal Structure Database (ICSD): accessibility in support of materials research and design, Acta Crystallogr. Sect. B: Struct. Sci. 58 (2002) 364-369.

[65] G. Shenoy, P. Viccaro, D.M. Mills. Characteristics of the 7-GeV advanced photon source: a guide for users, (1992).

[66] J. Ilavsky, P.R. Jemian. Irena: tool suite for modeling and analysis of small-angle scattering, J. Appl. Crystallogr. 42 (2009) 347-353.

[67] J. Naser, J. Smith Jr, A. Kuruvilla. Effect of microgravity on grain coarsening during liquid phase sintering in the $\mathrm{Fe}-\mathrm{Cu}$ system, Journal of materials science 33 (1998) 5573-5580.

[68] R. Wilson, P. Partridge. The nucleation and growth of S'precipitates in an aluminium-2.5\% copper-1.2\% magnesium alloy, Acta Metall. 13 (1965) 1321-1327.

[69] I.M. Lifshitz, V.V. Slyozov. The kinetics of precipitation from supersaturated solid solutions, J. Phys. Chem. Solids 19 (1961) 35-50.

[70] A. Deschamps, F. De Geuser, Z. Horita, S. Lee, G. Renou. Precipitation kinetics in a severely plastically deformed 7075 aluminium alloy, Acta Mater. 66 (2014) 105-117. 
[71] J.I. Rojas, D. Crespo. Modeling of the effect of temperature, frequency, and phase transformations on the viscoelastic properties of AA 7075-T6 and AA 2024-T3 Aluminum Alloys, Metall. Mater. Trans. A 43 (2012) 4633-4646.

[72] G.W. Smith. Precipitation kinetics in solutionized aluminum alloy 2124: Determination by scanning and isothermal calorimetry, Thermochim. Acta 317 (1998) 7-23.

[73] J. Lake. An iterative method of slit-correcting small angle X-ray data, Acta Crystallogr. 23 (1967) 191-194.

[74] J. Robson, P. Prangnell. Dispersoid precipitation and process modelling in zirconium containing commercial aluminium alloys, Acta Mater. 49 (2001) 599-613.

[75] J.W. Christian. The theory of transformations in metals and alloys, Newnes, 2002.

[76] M. Starink. The determination of activation energy from linear heating rate experiments: a comparison of the accuracy of isoconversion methods, Thermochim. Acta 404 (2003) 163-176.

[77] I. Khan, M. Starink, J.L. Yan. A model for precipitation kinetics and strengthening in $\mathrm{Al}-\mathrm{Cu}-\mathrm{Mg}$ alloys, Mater. Sci. Eng., A 472 (2008) 66-74.

[78] L. Kovarik, S. Court, H. Fraser, M. Mills. GPB zones and composite GPB/GPBII zones in Al$\mathrm{Cu}-\mathrm{Mg}$ alloys, Acta Mater. 56 (2008) 4804-4815.

[79] S. Wang, M. Starink. The assessment of GPB2/S" structures in Al-Cu-Mg alloys, Mater. Sci. Eng., A 386 (2004) 156-163.

[80] S. Wang, M. Starink, N. Gao. Precipitation hardening in Al-Cu-Mg alloys revisited [J], Scripta Mater. 54 (2006) 287-291.

[81] F. Zhang, A.J. Allen, L.E. Levine, D.C. Mancini, J. Ilavsky. Simultaneous multiplexed materials characterization using a high-precision hard X-ray micro-slit array, J. Synchrotron Radiat. 22 (2015) 653660 .

[82] X. Wu, P. Jiang, L. Chen, F. Yuan, Y.T. Zhu. Extraordinary strain hardening by gradient structure, Proc. Natl. Acad. Sci. U.S.A. 111 (2014) 7197-7201.

[83] S. Cao, J.-C. Zhao. Application of dual-anneal diffusion multiples to the effective study of phase diagrams and phase transformations in the Fe-Cr-Ni system, Acta Mater. 88 (2015) 196-206. 


\section{Figure Captions:}

Figure 1: TEM micrographs and associated diffraction patterns of phases identified in the AA2024 alloy in the TEM-226 condition: (1a) dark field image in $\left(\begin{array}{lll}-1 & 1 & -1\end{array}\right) \mathrm{S}$ and (1b) SAED pattern of (1a) with zone axis [ $\left[\begin{array}{lll}1 & -2 & -1\end{array}\right] \mathrm{Al} / /\left[\begin{array}{lll}1 & -3 & -4\end{array}\right] \mathrm{S}$; (2a) dark-field image in $\left(\begin{array}{lll}0 & 0 & -2\end{array}\right)$ $\mathrm{Al}_{12}(\mathrm{Fe}, \mathrm{Mn})_{3} \mathrm{Si}$ and (2b) SAED pattern of (2a) with zone axis [010] $\mathrm{Al}_{12}(\mathrm{Fe}, \mathrm{Mn})_{3} \mathrm{Si}$; (3a) darkfield image in (lll $\left.\begin{array}{lll}1 & 0 & 3\end{array}\right) \mathrm{Al}_{7} \mathrm{Cu}_{2} \mathrm{Fe}$ and (3b) SAED pattern of (3a) with zone axis [ $\left.\begin{array}{lll}-3 & 2 & 1\end{array}\right] \mathrm{Al}_{7} \mathrm{Cu}_{2} \mathrm{Fe}$; (4a) dark-field image in (-2 01 1) $\mathrm{Mg}_{2} \mathrm{Si}$ and SAED pattern of (4a) with zone axis $\left[\begin{array}{lll}1 & 0 & 2\end{array}\right] \mathrm{Mg}_{2} \mathrm{Si}$; (5a) dark-field image in (2 00 ) AlFeMgSi and (5b) SAED pattern of (5a) with zone axis [ $\left.\begin{array}{lll}0 & 1 & 2\end{array}\right]$ $\mathrm{AlFeMgSi}$; and (6a) dark-field image in ( $\left.\begin{array}{lll}1 & -1 & 1\end{array}\right) \mathrm{Al}_{2} \mathrm{Cu}$ and (6b) SAED pattern of (6a) with zone axis $\left[\begin{array}{lll}1 & 4 & 0\end{array}\right] \mathrm{Al}_{2} \mathrm{Cu}$.

Figure 2: An illustration of the combined slit-smeared USAXS, SAXS, and WAXS measurements. The SAXS and WAXS data are offset along the vertical axis for clarity. Here, USAXS, SAXS, and WAXS data were captured in sequence. The sample was SWAXS-226 under an isothermal ageing temperature of $226^{\circ} \mathrm{C}$. The duration of the USAXS measurements was $\approx 6$ min. The exposure times for SAXS and WAXS measurements were $20 \mathrm{~s}$ and $30 \mathrm{~s}$, respectively.

Figure 3: Combined USAXS and SAXS data from SWAXS-190, SWAXS-208, and SWAXS226 samples under isothermal ageing temperatures of $190^{\circ} \mathrm{C}, 208^{\circ} \mathrm{C}$, and $226^{\circ} \mathrm{C}$, respectively. The time difference between consecutive datasets was $\approx 12 \mathrm{~min}$. The inset in (c) shows the SAED TEM data upon heating to $226^{\circ} \mathrm{C}$. The diffuse scattering, highlighted by the arrows, is a signature of the formation of very small clusters

Figure 4: WAXS data from SWAXS-226 sample under an isothermal ageing temperature of 226 ${ }^{\circ} \mathrm{C}$. The duration of this series was approximately $10 \mathrm{~h}$. The time difference between consecutive measurements was $\approx 12$ min. To show the WAXS data with more clarity in (a), only one out of every five WAXS datasets is shown in this figure. The evolution of the diffraction peak near 2.45 $\AA^{-1}$ (S phase, 112 reflection) as a function of time with a linear intensity scale is presented in (b). The emergence of this peak is shown in the inset, with its FWHM shown in the main plot.

Figure 5: Phase identification of the in-situ WAXS data. Thick red and blue stick patterns refer to predicted peak positions for $\mathrm{CuMgAl}_{2}$ and $\mathrm{Cu}_{2} \mathrm{FeAl}_{7}$, respectively. Thin blue and red lines trace the data for the SWAXS-226 ${ }^{\circ} \mathrm{C}$ sample, measured initially and after $540 \mathrm{~min}$, respectively.

Figure 6: Evolution of the integrated peak intensity at $d=2.570 \AA$ ( or $q=2.445 \AA^{-1}$ ) at $190{ }^{\circ} \mathrm{C}$, $208{ }^{\circ} \mathrm{C}$, and $226^{\circ} \mathrm{C}$, respectively. This peak corresponds to the 112 reflection of the $\mathrm{S}$ phase precipitate. Estimated standard deviation uncertainties are within $\pm 5 \%$ of the values shown in the figure. 
Figure 7: Illustrations of the SAXS model components used in the data analysis. The low- $q$ power law represents baseline scattering from larger microstructures that the available $q$ range cannot completely resolve. (a) Data and their fits at the start and end of the in situ ageing treatment at $208^{\circ} \mathrm{C}$. This highlights that initially, only spherical clusters were present. At the end of the ageing treatment, the scattering intensity above the baseline is solely accounted for by $\mathrm{S}$ phase precipitates. (b) Data and associated fit acquired at $72 \mathrm{~min}$ into the in situ ageing treatment at $208^{\circ} \mathrm{C}$. This intermediate dataset clearly shows the simultaneous contributions from the baseline, clusters, and the $\mathrm{S}$ phase precipitates to the acquired scattering intensity.

Figure 8: Evolution of (a) the scattering volume of the S precipitates, (b) nominal LSW thickness of the $\mathrm{S}$ precipitates, and (c) the scattering volume of the clusters, during isothermal ageing treatments at $190{ }^{\circ} \mathrm{C}, 208^{\circ} \mathrm{C}$, and $226^{\circ} \mathrm{C}$, respectively. Estimated one $\sigma$ uncertainties are within $\pm 2.5 \%$ of the values shown on the plots. The solid curves in Figure 8(c) represent least-squares fits of the data using an equation form of $V=V_{0}+C \times \exp (-\kappa \times t)$, where $t$ is time and $\kappa$ is a temperature-dependent kinetic reaction rate.

Figure 9: Arrhenius analysis of the cluster-dissolution rates determined using the analysis shown in Figure 8(c). Vertical bars are computed standard deviation uncertainties from fits.

Figure 10: (a) Scattering volume fraction of the $\mathrm{S}$ precipitates as functions of time, determined by scattering invariant analyses (estimated one $\sigma$ uncertainties are within $\pm 2.5 \%$ of the values shown on the plots). The solid curves represent least-squares fits of the data using an equation form of $V=V_{0}-C \times \exp (-\kappa \times t)$, where $t$ is time and $\kappa$ is a temperature-dependent kinetic reaction rate. (b) Arrhenius analysis of the reaction rates. Vertical bars are computed standard deviation uncertainties from fits. (c) $V_{0}$ vs. temperature.

Figure 11: Equilibrium phase fractions as function of temperature as predicted using the TCAL4 thermodynamic database. The dashed green line represents the solution treatment temperature and the two dashed red lines indicate the temperature range for the aging studies.

Figure 12. Volume fraction of $\mathrm{S}$ phase as a function time at the $190{ }^{\circ} \mathrm{C}, 208{ }^{\circ} \mathrm{C}$ and $226{ }^{\circ} \mathrm{C}$ ageing temperatures, as predicted using TC-PRISMA with TCAL4 and TCMOB3. (a) with a linear scale to compare with the experiments in Figure 8 (a), and (b) with log time scale to compare the precipitation process at the different times. 


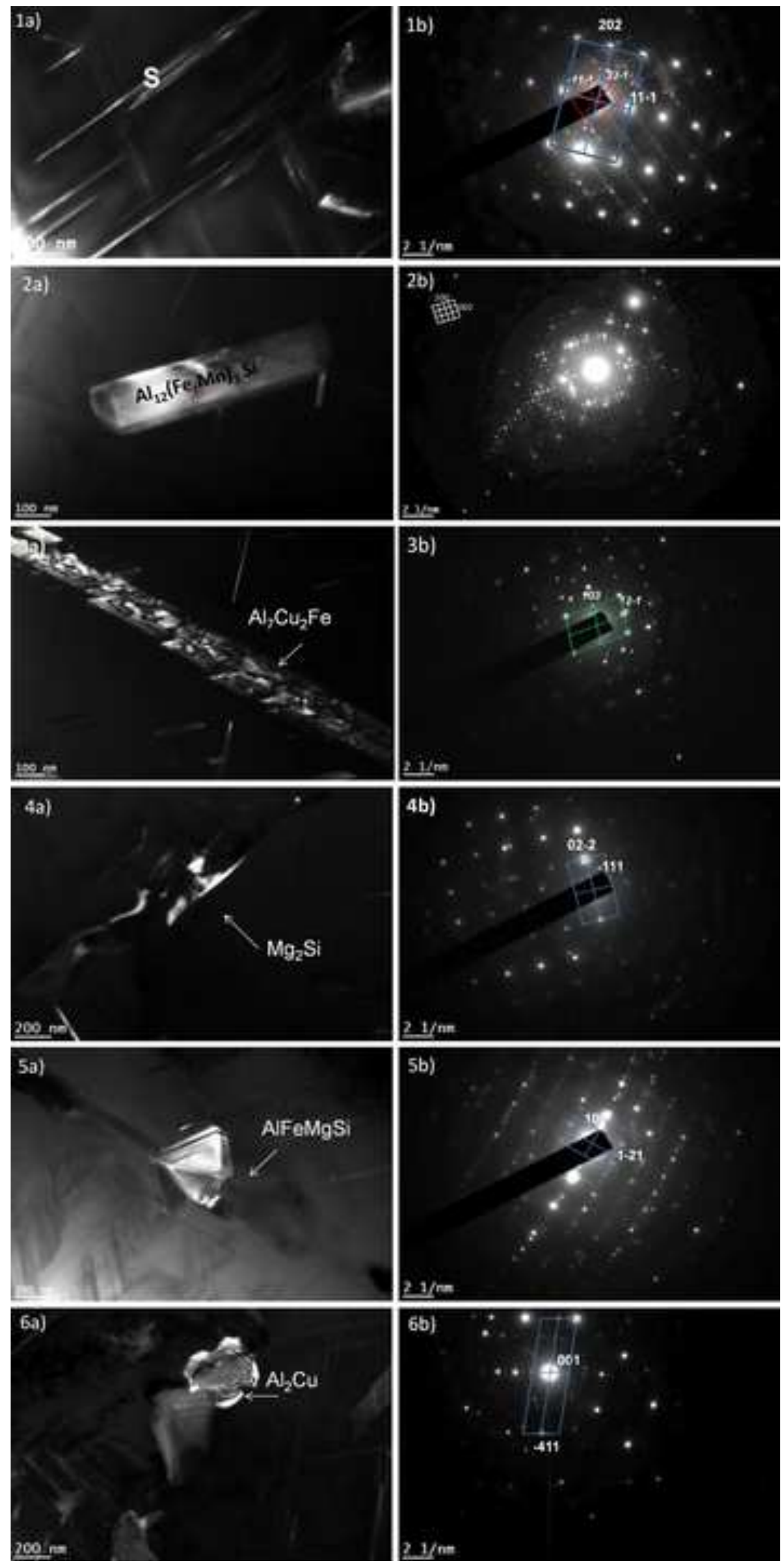




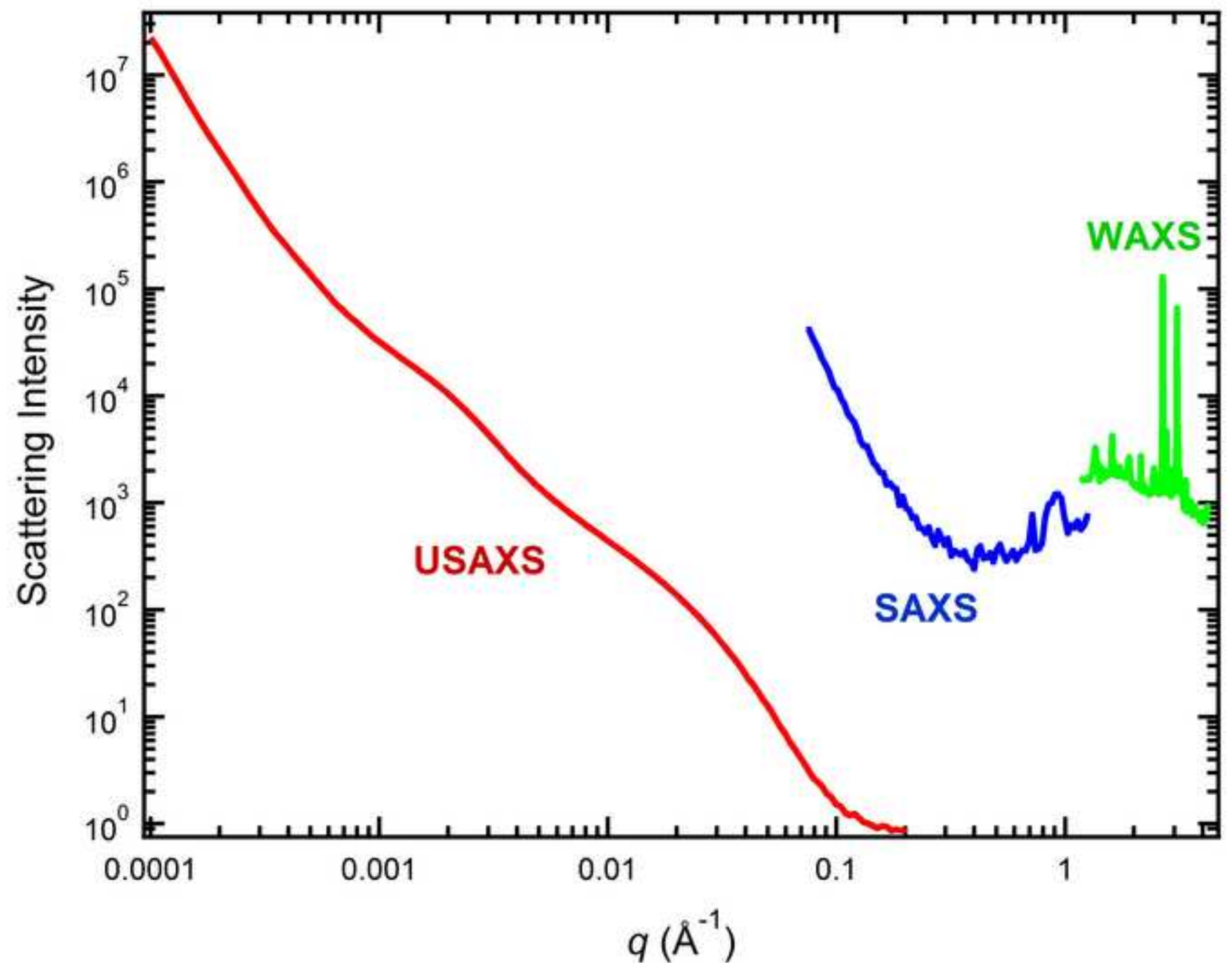



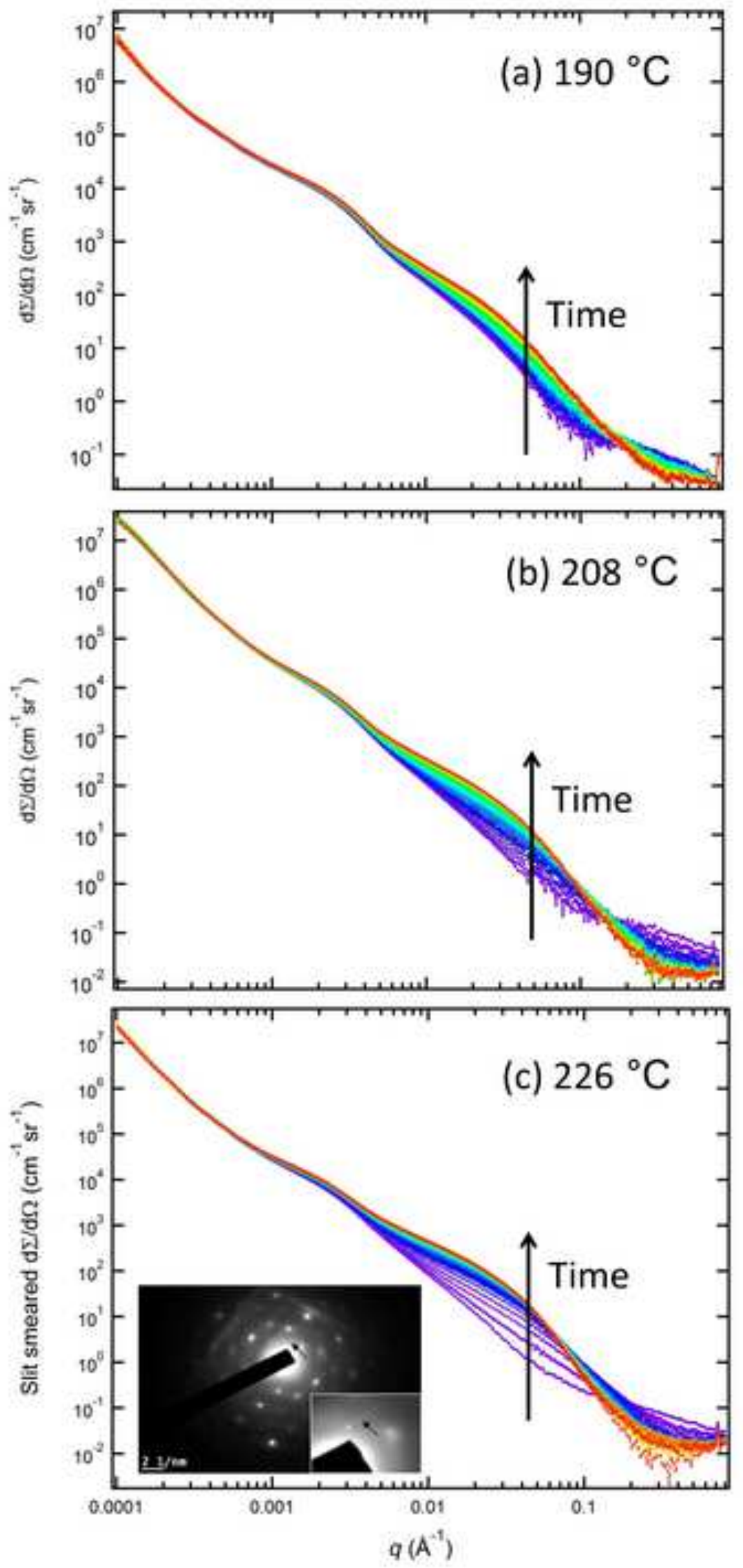

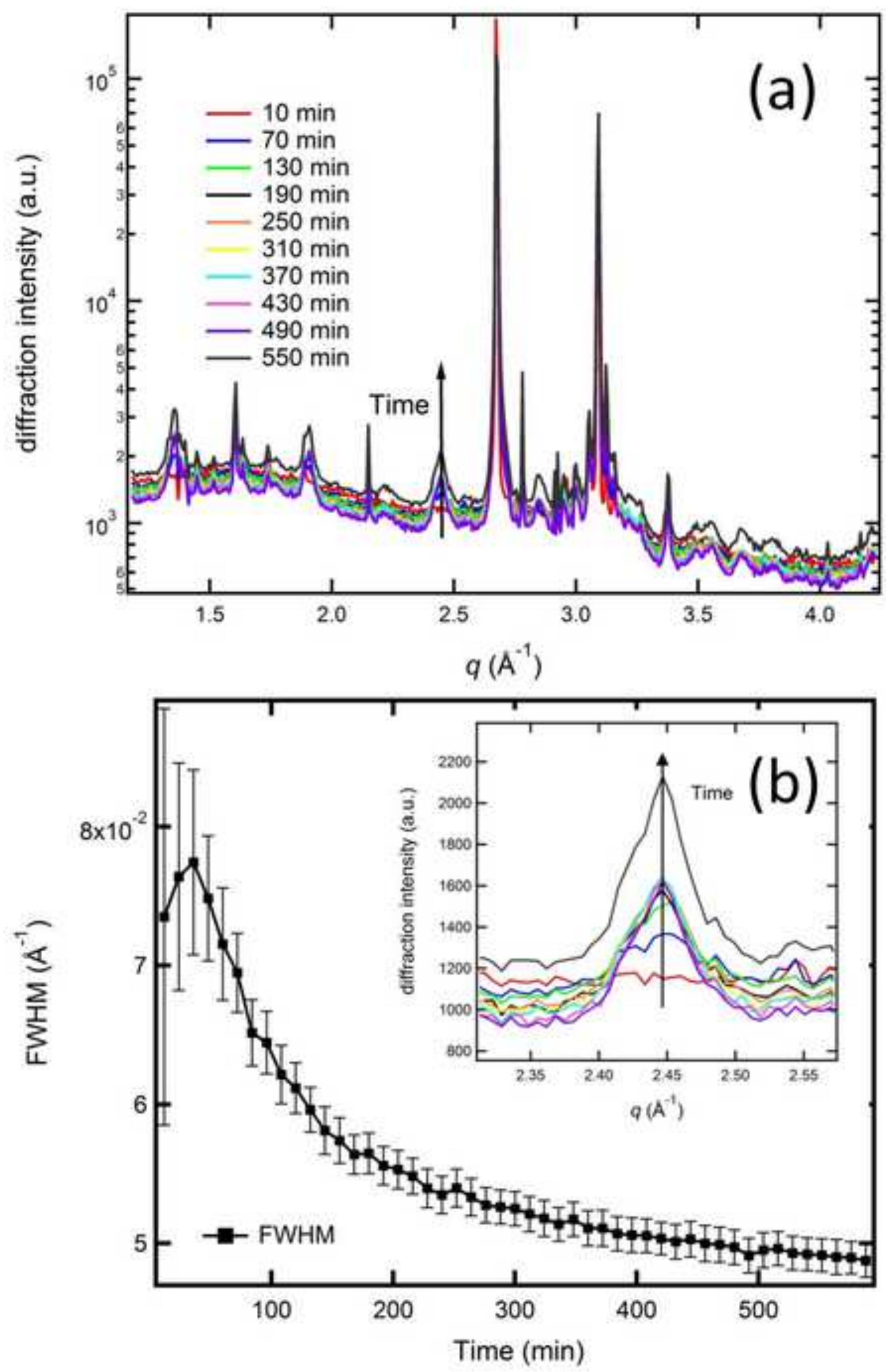


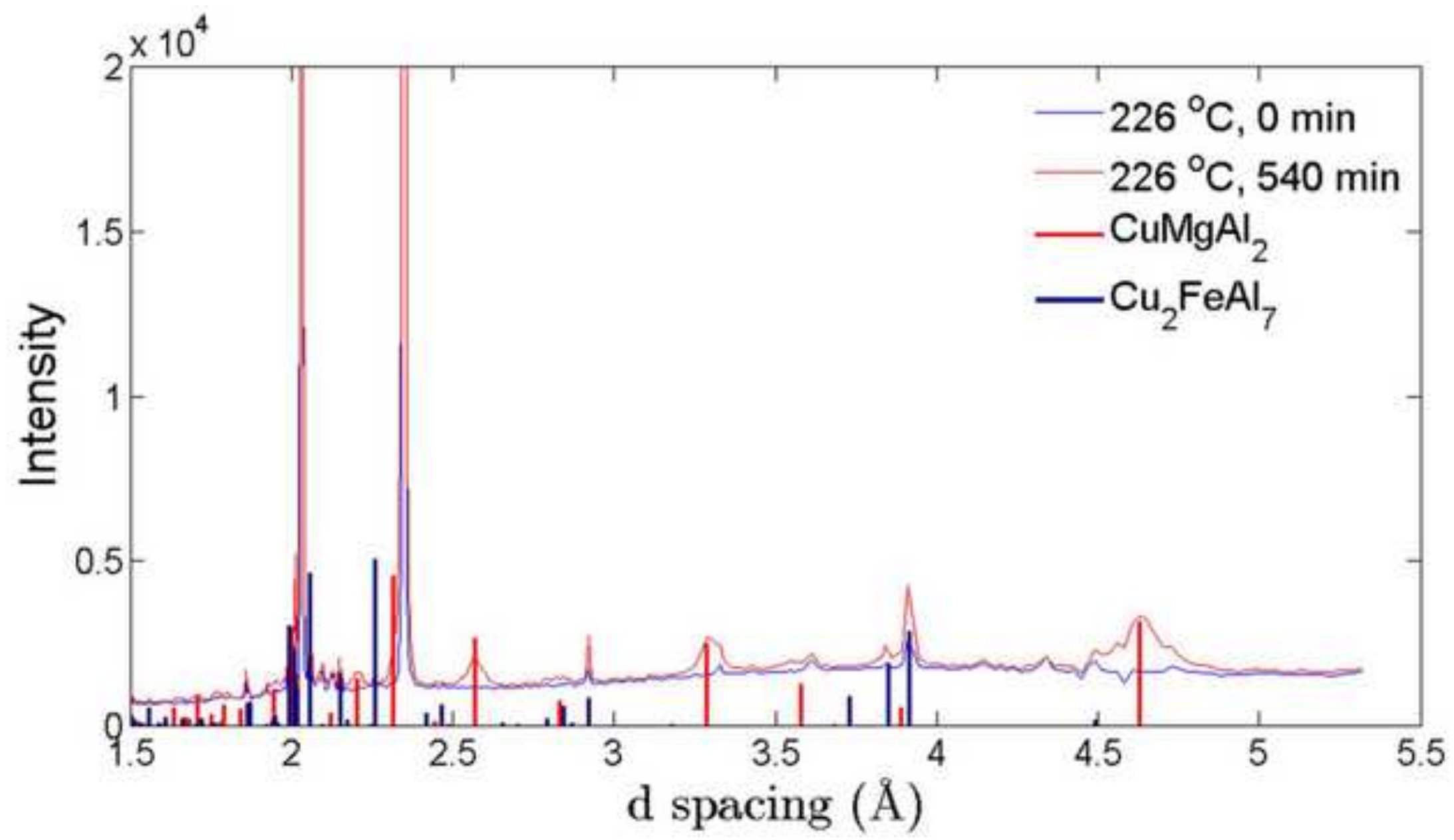




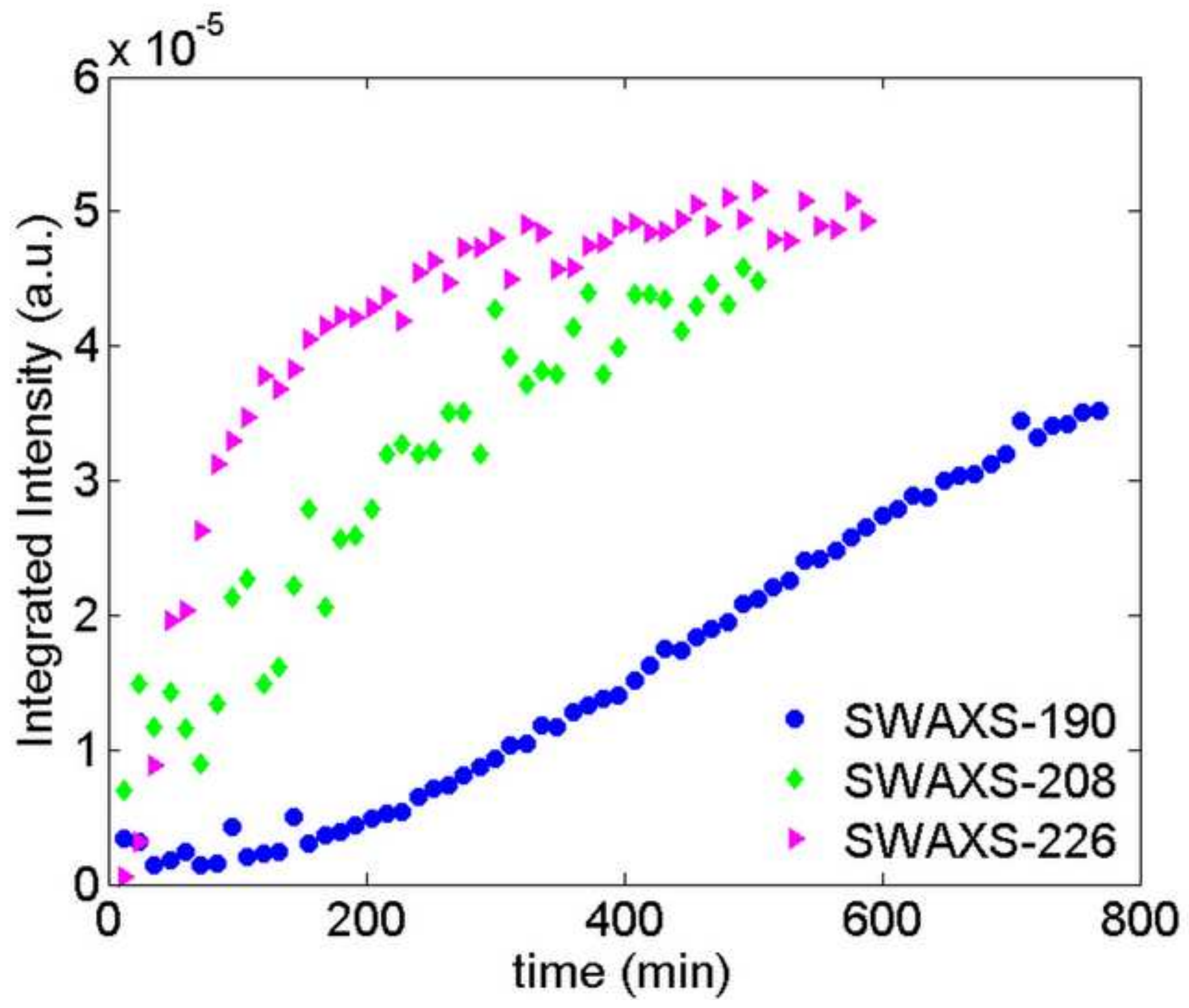



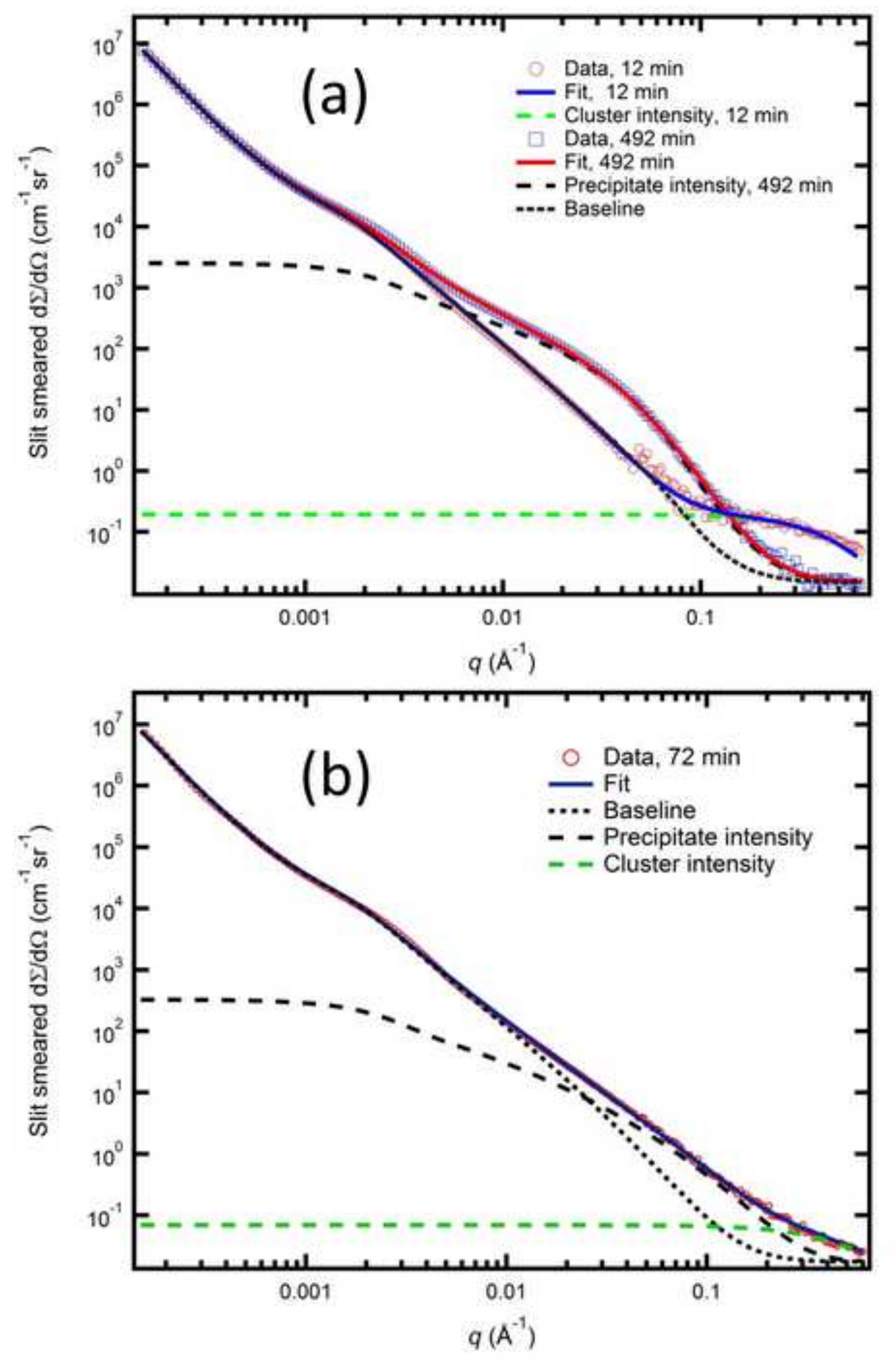

Figure_07

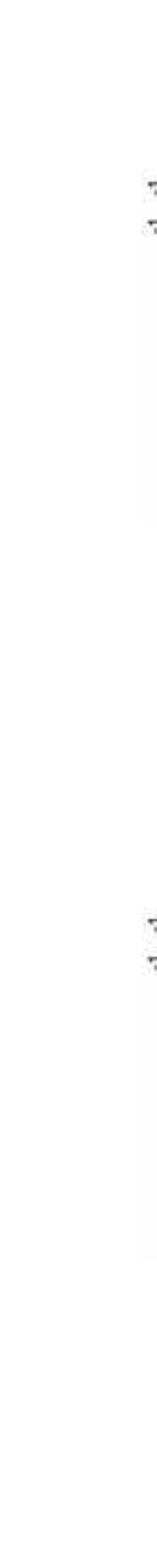
$-1$

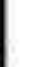

Figure_07 

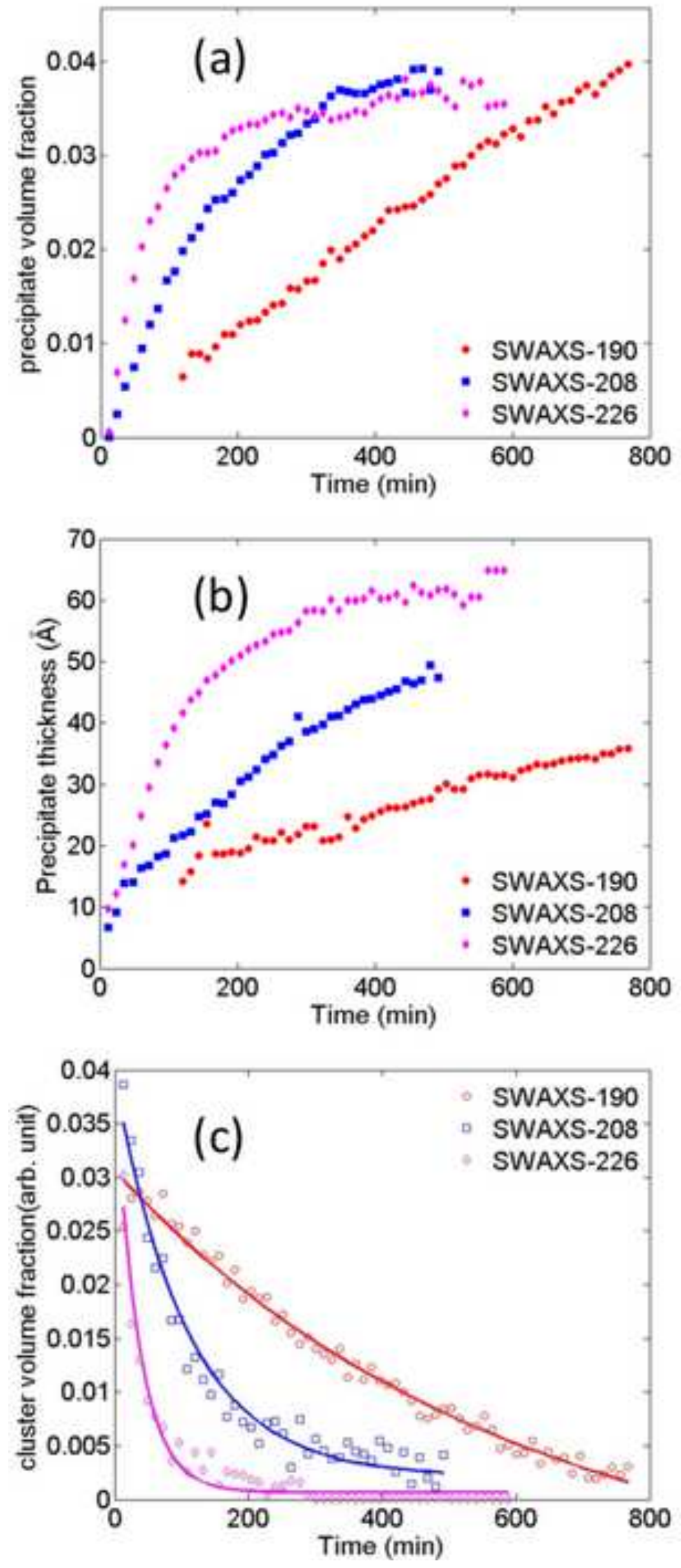


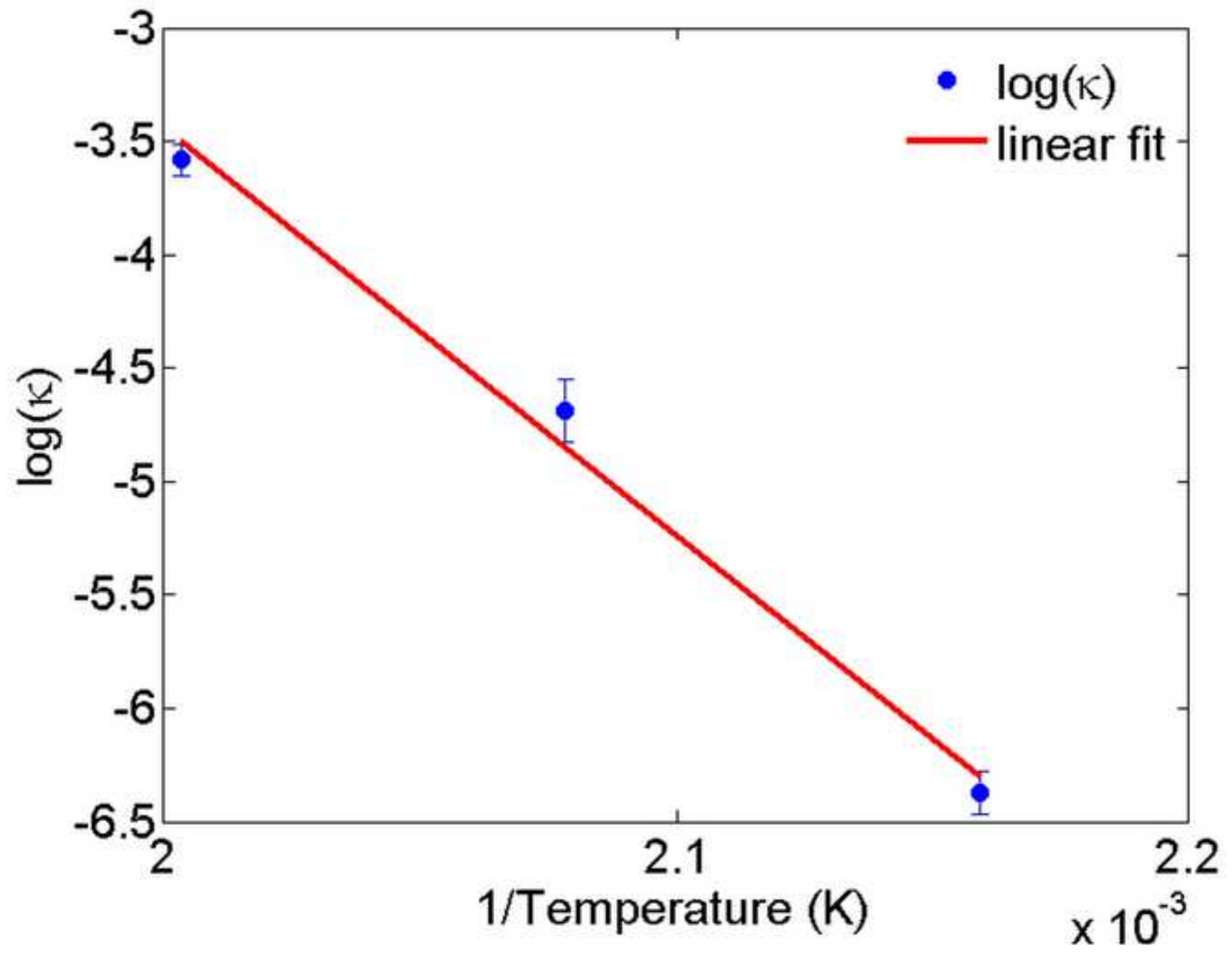



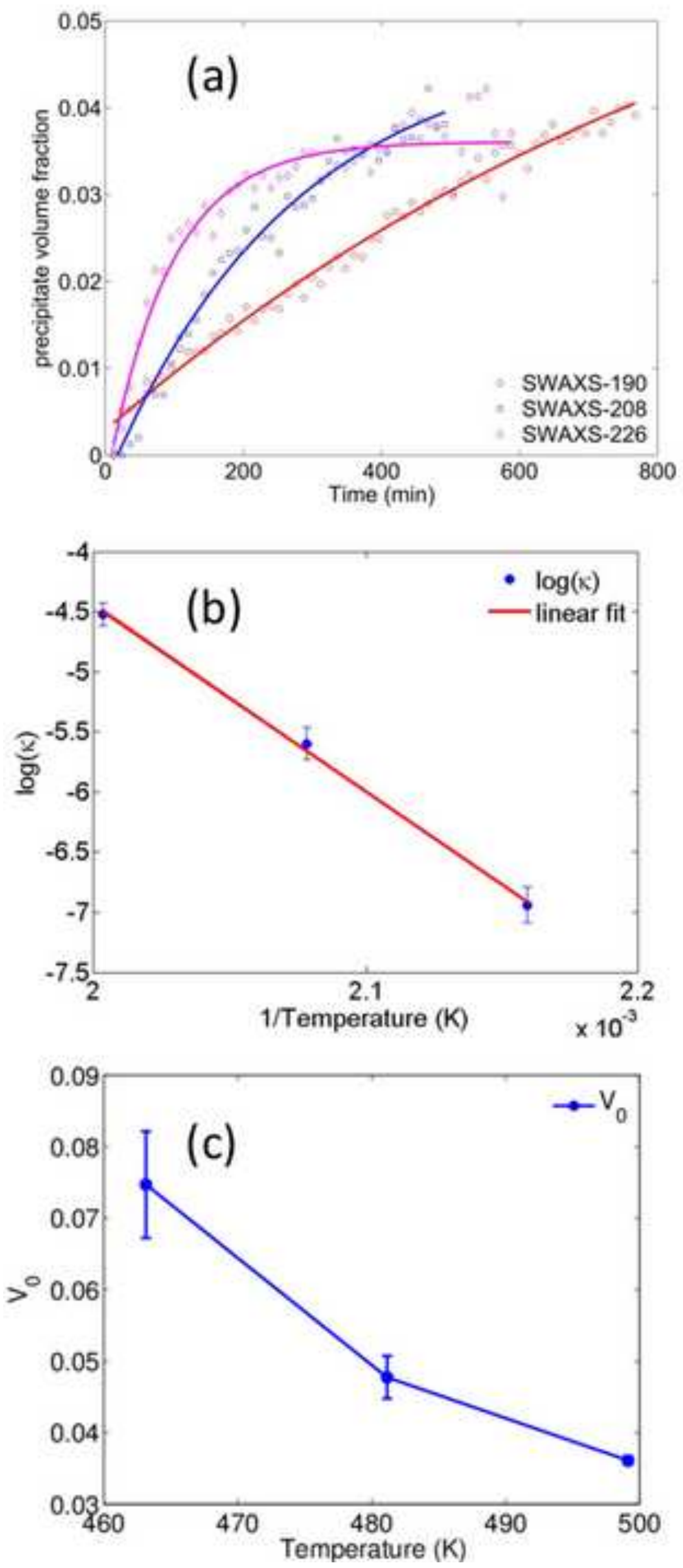


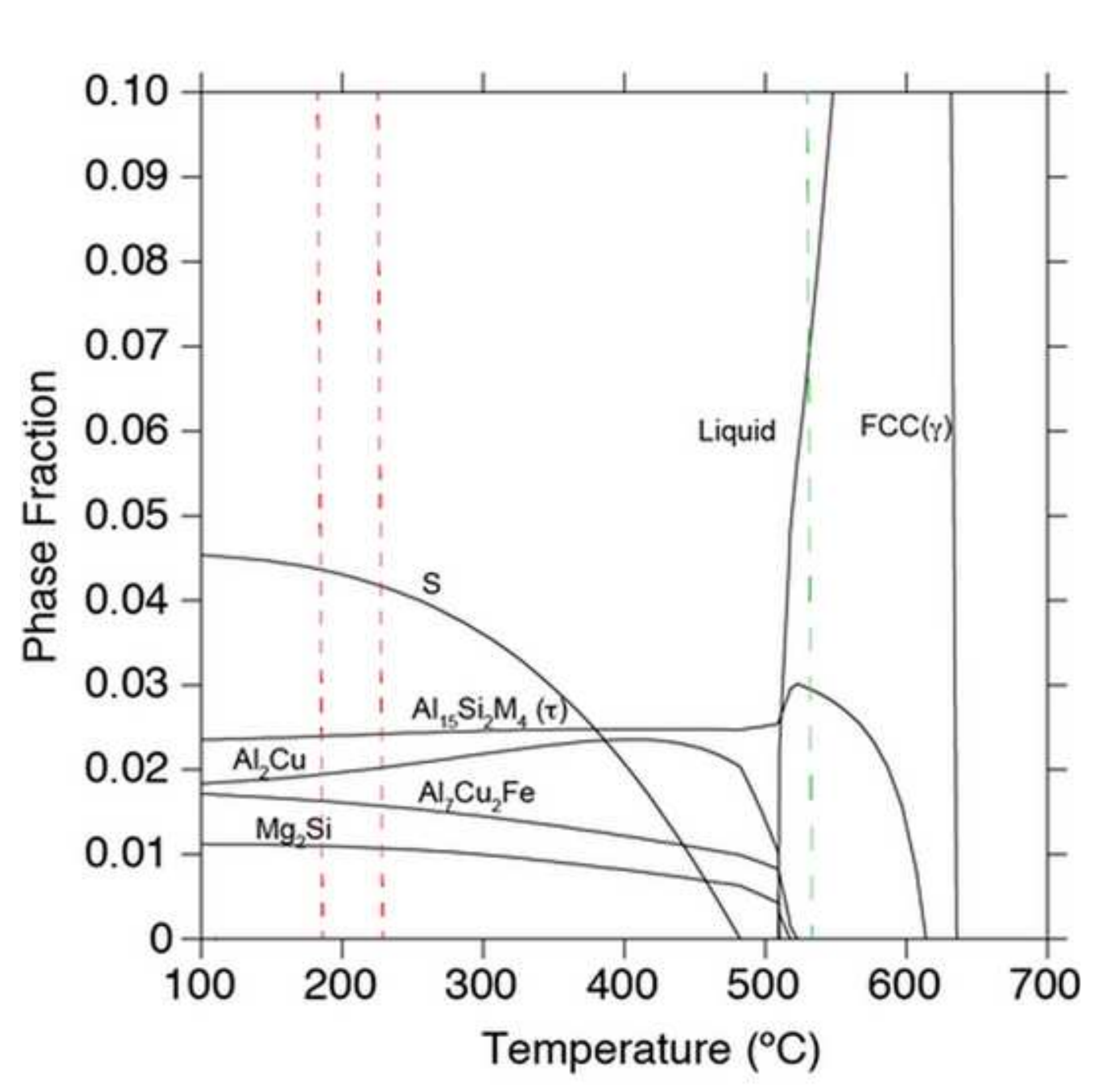

Figure_11 
Figure_12
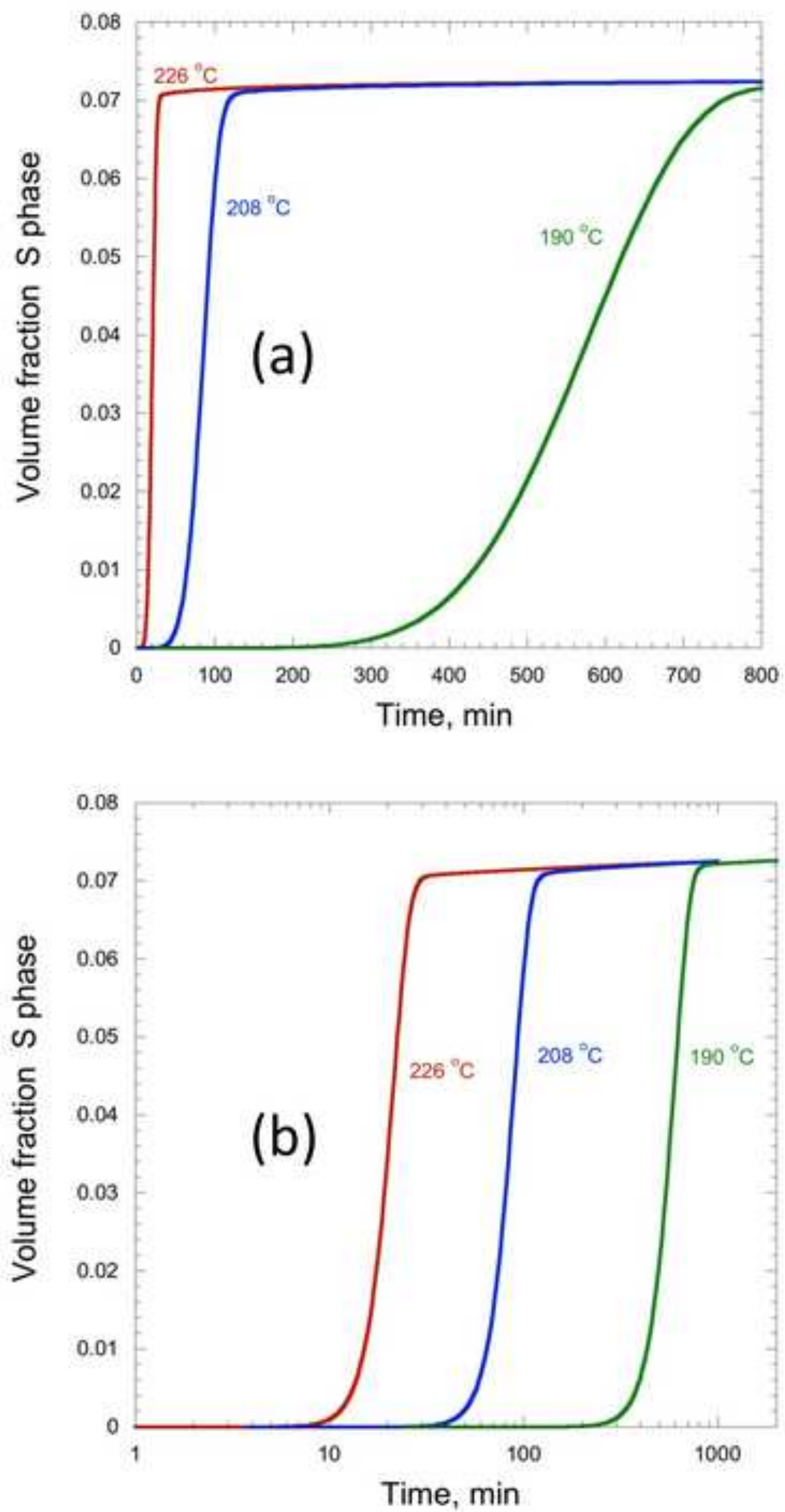


\begin{tabular}{lllllllllllll}
\hline Alloy & $\mathrm{Cu}$ & $\mathrm{Mg}$ & $\mathrm{Mn}$ & $\mathrm{Si}$ & $\mathrm{Fe}$ & $\mathrm{Ti}$ & $\mathrm{Zn}$ & $\mathrm{Pt}$ & $\mathrm{Ni}$ & $\mathrm{Sn}$ & $\mathrm{Cr}$ & $\mathrm{Al}$ \\
$\mathrm{AA2024}$ & 4.77 & 1.65 & 0.79 & 0.48 & 0.36 & 0.05 & 0.05 & $<0.05$ & 0.08 & 0.06 & $<0.05$ & balance \\
\hline
\end{tabular}

Table 1: Chemical composition of AA2024 alloy (mass \% of total)

\begin{tabular}{|l|l|}
\hline $\begin{array}{l}\text { Designated } \\
\text { names }\end{array}$ & Details \\
\hline SWAXS-190 & $\begin{array}{l}\mathrm{T} 3+\text { solutionized at } 535{ }^{\circ} \mathrm{C} \text { for } 5 \mathrm{~h}+\text { water quenched }+ \text { heated to } 190{ }^{\circ} \mathrm{C} \text { at } \\
50{ }^{\circ} \mathrm{C} / \mathrm{min}+\text { annealing at } 190{ }^{\circ} \mathrm{C}\end{array}$ \\
\hline SWAXS-208 & $\begin{array}{l}\mathrm{T} 3+\text { solutionized at } 535^{\circ} \mathrm{C} \text { for } 5 \mathrm{~h}+\text { water quenched }+ \text { heated to } 208^{\circ} \mathrm{C} \text { at } \\
50{ }^{\circ} \mathrm{C} / \mathrm{min}+\text { annealing at } 208{ }^{\circ} \mathrm{C}\end{array}$ \\
\hline SWAXS-226 & $\begin{array}{l}\mathrm{T} 3+\text { solutionized at } 535^{\circ} \mathrm{C} \text { for } 5 \mathrm{~h}+\text { water quenched }+ \text { heated to } 226{ }^{\circ} \mathrm{C} \text { at } \\
50{ }^{\circ} \mathrm{C} / \text { min }+ \text { annealing at } 226{ }^{\circ} \mathrm{C}\end{array}$ \\
\hline TEM-226 & $\begin{array}{l}\mathrm{T} 3+\text { solutionized at } 535{ }^{\circ} \mathrm{C} \text { for } 5 \mathrm{~h}+\text { water quenched }+ \text { heated to } 226{ }^{\circ} \mathrm{C} \text { at } \\
50{ }^{\circ} \mathrm{C} / \text { min }+ \text { annealing at } 226{ }^{\circ} \mathrm{C} \text { for } 9 \text { hours }+ \text { water quenched }\end{array}$ \\
\hline
\end{tabular}

Table 2: Heat treatment procedures for the USAXS/SAXS/WAXS samples and TEM sample.

\begin{tabular}{|l|l|l|}
\hline Phase & Crystal Structure & Lattice parameter $(\AA)$ \\
\hline $\mathrm{Al}_{12}(\mathrm{Fe}, \mathrm{Mn}) 3 \mathrm{Si}$ & $\mathrm{Im} 3$ & $\mathrm{a}=12.6$ \\
\hline $\mathrm{Al}_{7} \mathrm{Cu}_{2} \mathrm{Fe}$ & $\mathrm{P} 4 / \mathrm{mnc}$ (tetragonal) & $\mathrm{a}=6.32, \mathrm{c}=14.76$ \\
\hline $\mathrm{Mg}_{2} \mathrm{Si}(\beta)$ & $\mathrm{Fm}-3 \mathrm{~m}$ & $\mathrm{a}=6.34$ \\
\hline $\mathrm{Al}_{2} \mathrm{Cu}(\theta)$ & $\mathrm{I} / \mathrm{mcm}$ (tetragonal) & $\mathrm{a}=6.03, \mathrm{c}=4.86$ \\
\hline $\mathrm{AlFeMgSi}_{\mathrm{CuMgAl}}(\mathrm{S})$ & $\mathrm{P} 6 / \mathrm{mmm}$ (hex) & $\mathrm{a}=6.62, \mathrm{c}=14.63$ \\
\hline $\mathrm{C} \mathrm{cm}$ & $\mathrm{a}=3.93, \mathrm{~b}=9.42, \mathrm{c}=7.16$ \\
\hline $\mathrm{Al}(\alpha)$ & $\mathrm{Fm}-3 \mathrm{~m}$ & $\mathrm{a}=4.01$ \\
\hline
\end{tabular}

Table 3: Phase compositions for AA2024 alloy, determined from TEM results from the TEM226 sample. 


\begin{tabular}{|l|l|l|l|}
\hline & $\begin{array}{l}\text { Mass density } \\
\left(\times 10^{3} \mathrm{~kg} / \mathrm{m}^{3}\right)\end{array}$ & $\begin{array}{l}\text { Scattering length density } \\
\left(10^{14} \mathrm{~m}^{-2}\right)\end{array}$ & $\begin{array}{l}\text { Scattering contrast with respect to Al } \\
\left(10^{28} \mathrm{~m}^{-4}\right)\end{array}$ \\
\hline $\mathrm{Al}$ & 2.7 & 22.08 & 0 \\
\hline $\mathrm{CuMgAl}_{2}$ & 3.57 & 28.62 & 42.77 \\
\hline
\end{tabular}

Table 4: Scattering length densities and contrasts of the matrix and S precipitates.

\begin{tabular}{|l|l|}
\hline Temperature $\left({ }^{\circ} \mathbf{C}\right)$ & $\boldsymbol{\kappa}\left(\mathbf{m i n}^{-1}\right)$ \\
\hline 190 & $0.00171 \pm 0.00016$ \\
\hline 208 & $0.00920 \pm 0.00116$ \\
\hline 226 & $0.02787 \pm 0.00193$ \\
\hline
\end{tabular}

Table 5: Dissolution kinetic rate analysis of the scattering volumes of the clusters at different temperatures.

\begin{tabular}{|l|l|l|}
\hline Temperature $\left({ }^{\circ} \mathbf{C}\right)$ & $\boldsymbol{\kappa}\left(\mathbf{m i n}^{-1}\right)$ & $\boldsymbol{V}_{\boldsymbol{0}}$ \\
\hline 190 & $0.00097 \pm 0.00014$ & $0.0747 \pm 0.0076$ \\
\hline 208 & $0.00370 \pm 0.00049$ & $0.0477 \pm 0.0030$ \\
\hline 226 & $0.01087 \pm 0.00104$ & $0.0361 \pm 0.0006$ \\
\hline
\end{tabular}

Table 6: Precipitation kinetic rate analysis of the scattering volumes of S precipitates at different temperatures. 

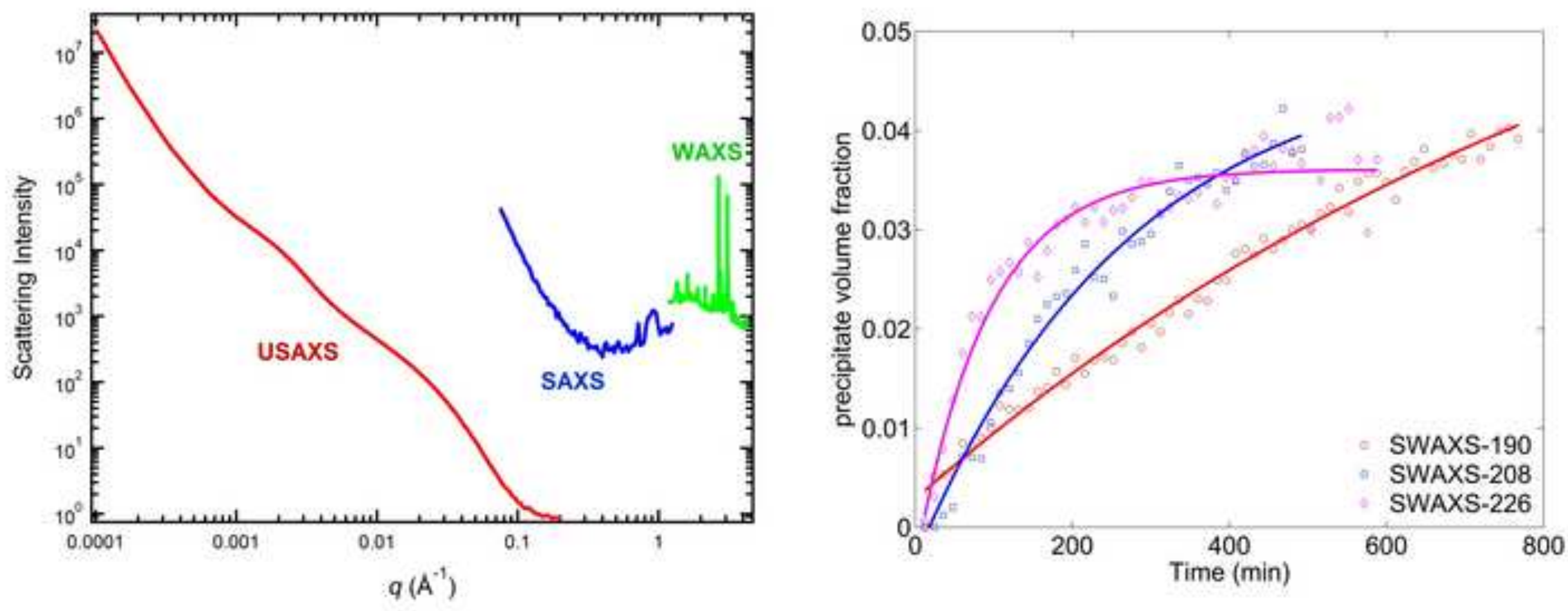